NBSIR 78-1584

\title{
Submarine Compartment Fire Study-Fire Performance Evaluation of Hull Insulation
}

B. T. Lee and J. N. Breese

Center for Fire Research National Engineering Laboratory National Bureau of Standards Washington, DC 20234

May 1979

Final Report

Prepared for:

Ship Damage Prevention and Control Naval Sea Systems Command Department of the Navy Washington, DC 20362 

NBSIR 78-1584

\section{SUBMARINE COMPARTMENT FIRE STUDY-FIRE PERFORMANCE EVALUATION OF HULL INSULATION}

B. T. Lee and J. N. Breese

Center for Fire Research

National Engineering Laboratory

National Bureau of Standards

Washington, DC 20234

May 1979

Final Report

Prepared for:

Ship Damage Prevention and Control

Naval Sea Systems Command

Department of the Navy

Washington, DC 20362

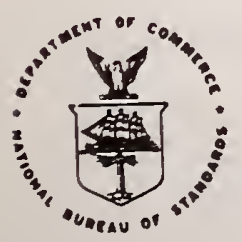

U.S. DEPARTMENT OF COMMERCE, Juanita M. Krops, Secrotary Jordan J. Baruch, Assistant Secretary for Science and Technology NATIONAL BUREAU OF STANDARDS. Ernest Ambler, Director 
1. INTRODUCTION

2. FACILITIES AND EXPERIMENTAL TESTS . . . . . . . . . . . . . . . . . 2

2.1 Full size Compartment Fires . . . . . . . . . . . . . . . . 2

2.2 Quarter-Scale Compartment Fires . . . . . . . . . . . . 3

2.2.1 Modeling Principles . . . . . . . . . . . . . 3

2.2.2 Model Experiments . . . . . . . . . . . . . . 4

2.3 Laboratory Tests of Fire Properties . . . . . . . . . . . 5

3. RESULTS AND DISCUSSIONS . . . . . . . . . . . . . . . . . . 5

3.1 Assessment of Potential Fire Performance of Materials . . . . 5

3.1.1 Laboratory Fire Test Evaluation . . . . . . . . . . . 5

3.1.1.1 Ease of Ignition . . . . . . . . . . . . . 5

3.1.1.2 Flame Spread.................. . 5

3.1.1.3 Heat Release... . . . . . . . . . . . . 6

3.1.2 Quarter-Scale Compartment Fire Testing . . . . . . . . 7

3.1.2.1 Evaluation of Unprotected Hull Insulation . . . 7

3.1.2.2 Evaluation of Some Fire Protective Coatings . . 8

3.1.2.3 Generation of Combustion Gases . . . . . . . . 9

3.1.3 Relationship between Laboratory Fire Tests and Compartment Fire Tests . . . . . . . . . . . . . 9

3.2 Comparison of Full- and Quarter-Scale compartment Fires . . . 10

3.2.1 Fire Buildup .. . . . . . . . . . . . . . . 10

3.2.2 Supporting Measurements . . . . . . . . . . . . . 11

3.2.2.1 Thermal Fluxes . . . . . . . . . . . . . . . 11

3.2.2.2 Interior and Doorway Air Temperature

3.2.2.3 Air Velocity and Mass Balance across Doorway : 12

3.2.2.4 Combustion Products ........... 12

4. CONCLUSIONS • . . . . . . . . . . . . . . . . . . . 13

5. RECOMMENDATIONS . . . . . . . . . . . . . . . . . . . 13

6. ACKNOWLEDGMENTS . . . . . . . . . . . . . . . . . . . If

7. REFERENCES . . . . . . . . . . . . . . . . . . . . 14

8. APPENDIX - LABORATORY FIRE TESTS . . . . . . . . . . . . . . 16

8.1 Ease of Ignition... . . . . . . . . . . . . . . 16

8.2 ASTM E 84 Flame Spread . . . . . . . . . . . . . . . 16

8.3 ASTM E 162 Flame Spread . . . . . . . . . . . . . . 17

8.4 Rate of Heat Release Calorimeter . . . . . . . . . . . . 17

8.5 Potential Heat Test . . . . . . . . . . . . . 17 
Figure 1. Plan view of compartment arrangement showing locations of ignition burner and instrumentation . . . . . . . . . 19

Figure 2A. Quarter-scale compartment fire test prior to ignition . . 20

Figure 2B. Quarter-scale compartment fire test at flashover . . . . . 20

Figure 3. Top of doorway air temperature histories for several prototype fires and model tests using lintel III. . . . . 21

Figure 4. Compartment air temperature profiles at time of peak doorway air temperature . . . . . . . . . . . . 22

Figure 5. Doorway air temperature profiles at time of peak doorway air temperature............... . 22

Figure 6. Doorway velocity profiles for full-scale tests FS-l

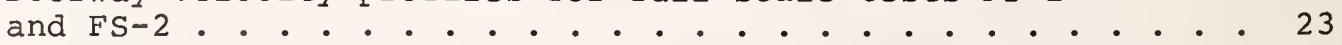

Figure 7. Doorway velocity profiles for full-scale test FS-4 . . . . . 24

Figure 8 Carbon monoxide concentrations along doorway at time of peak doorway air temperature........... . 25

Figure 9. Oxygen depletion profile along doorway at time of peak doorway air temperature ............. . . 25

Figure 10. Proposed submarine fire test compartment with frame bays . . 26 
Table 1. Materials used in the compartment and laboratory fire

tests..........................

Table 2. Summary of full-scale tests and counterpart model tests .

Table 3. Summary of model tests, scaled height above doorway (lintel I) ..................... 29

Table 4. Model doorway dimensions . . . . . . . . . . . . . 30

Table 5. Summary of model tests, 1.4 times scaled height above doorway (lintel II)... . . . . . . . . . . . 31

Table 6. Model tests of fire barrier coatings . . . . . . . . . . . 32

Table 7. Summary of model tests, 1.8 times scaled height above doorway (lintel III) . . . . . . . . . . . . . .

Table 8A. Ease of ignition and flame spread properties of materials used in compartment fire tests . . . . . . . . . . . 34

Table $8 \mathrm{~B}$. Heat release rate and potential heat of materials used in compartment fire tests... . . . . . . . . . . .

Table 9A. Ease of ignition and flame spread properties of other submarine insulation materials . . . . . . . . . . 36

Table 9B. Heat release rate of other submarine insulation materials...................... . 37

Table 10. Comparison of compartment air temperatures for fire tests with three different doorway openings . . . . . . . 37

Table 11. Concentrations of some combustion gases at top of doorway...................... 38

Table 12. Comparison of fire buildup in full-scale and corresponding quarter-scale compartments . . . . . . . . 39

Table 13. Flux measurements at time of peak doorway temperature . . 39

Table 14. Calculated mass balance across doorway for three compartment fires............... . 40

Table 15. Comparison of measured model and prototype inflow air velocities near bottom of doorway

Table 16. Carbon monoxide, carbon dioxide, and oxygen concentrations and smoke measurements at doorway at time of peak doorway temperature . . . . . . . .

Table 17. Relative concentrations of some combustion gases at top of doorway for prototype and counterpart model tests 
In view of the present accepted engineering practice in this country, we assist the readers interested in making use of the U. S. units by giving conversion factors applicable to the metric SI system of units used in this report.

Length

$$
\begin{aligned}
& 1 \text { meter }=39.37 \mathrm{in} \\
& 1 \text { meter }=3.28 \mathrm{ft}
\end{aligned}
$$

Mass

$$
1 \mathrm{~kg}=2.20 \mathrm{lb}
$$

Temperature

Temperature in ${ }^{\circ} \mathrm{C}=5 / 9$ (temperature in ${ }^{\circ} \mathrm{F} 32$ )

Energy

$1 \mathrm{~kJ}=0.948 \mathrm{Btu}$

Power

$1 \mathrm{~kW}=0.948 \mathrm{Btu} / \mathrm{s}$ 
SUBMARINE COMPARTMENT FIRE STUDY-FIRE PERFORMANCE EVALUATION OF HULL INSULATION

B. T. Lee and J. N. Breese

\begin{abstract}
Certain foam rubber materials which are currently used to insulate the interior of submarines are shown to possess a serious fire risk potential. Flame spread tests often do not adequately reflect the fire hazard potential of these materials. It is shown that compartment fire testing is the only satisfactory method of evaluating these kinds of materials at the present time.
\end{abstract}

Fire barrier coatings for protecting these hull insulations are also investigated. Two candidate coatings are found to prevent full fire involvement of an insulated compartment following a moderately large flame exposure and at the same time meet the Navy's elasticity requirement for submarine application. The study includes comparisons of model and prototype compartment fire behavior and demonstrates the practicality of using quarter-scale fire tests for screening compartment finish materials.

Key words: Combustion products; fire barrier coatings; fire growth; flame spread; foam insulation; heat release; interior finish; laboratory fire tests; material ignitability; submarine compartment.

\title{
1. INTRODUCTION
}

Fire could represent a major threat to a submarine and to the life safety of its crew. The spread of heat, smoke and potentially hazardous combustion gases from a growing fire could overwhelm the normal cooling and filtering systems. This danger is accentuated because of the confined space and the limited, if any, means of securing refuge from the combustion products. It is essential that any incipient fire be confined to its neighborhood of origin or at least to a relatively small portion of the submarine for a sufficient time to permit suppression of the fire.

Hull insulation materials provide a large area for exposure to an accidental fire aboard a submarine. To help contain the fire the interior finish materials must not contribute significantly to the fire growth and spread. Unfortunately, the fire performance of such materials is difficult to assess solely on the basis of laboratory fire tests. In many instances, the potential fire behavior of interior finish can be adequately appraised only with compartment fire testing of the materials. However, such full-scale testing is expensive, particularly when many materials are to be evaluated.

For the preliminary evaluation of materials, a suitable alternative to full size compartment fire tests is the use of reduced-size model compartment fire tests. Full-scale tests would be used only for confirmation of the important model test results, and the data from the full-scale tests could be used to improve the model. This approach would thus reduce the amount of full-scale testing needed in the future.

The work discussed in this report has the following objectives: 
(1) To evaluate the potential fire hazards of the polyvinyl chloride (PVC) nitrile rubber insulations, which are currently used for submarine insulation,

(2) To ascertain the effectiveness of candidate commercial fire barrier materials for protecting such insulations from fire, and

(3) To develop a suitable one-quarter size compartment fire test for evaluating the fire performance of submarine hull insulation.

This report describes the full-scale compartment fire tests of some protected and unprotected hull insulations and the quarter-scale modeling of these fires. The work included quarter-scale compartment fire test comparison of additional hull insulations and screening of candidate fire protective materials. Laboratory fire test results on the ignitability, surface flammability and heat release are also given and compared with the performance observed in the compartment fire tests. In this study the basic criterion adopted for limiting fire growth required that the insulation and coating materials, when subjected to a moderately large ignition exposure, must not lead to flashover of the compartment. Flashover is defined here as the compartment condition where the radiation level becomes high enough to spontaneously ignite light combustible materials such as newspaper in the lower half of the compartment.

\section{FACILITIES AND EXPERIMENTAL TESTS}

\subsection{Full Size Compartment Fires}

Compartment fire tests of selected submarine hull insulation materials were performed in a $3.0 \times 3.0 \times 2.3 \mathrm{~m}$ high compartment having doorway dimensions of $0.73 \times 1.93 \mathrm{~m}$ high. Figure 1 is a plan view of the compartment showing the location of instrumentation. All four bulkheads and the overhead had $0.64 \mathrm{~cm}$ thick aluminum alloy plate or sheet mounted over $5.1 \times 10.2 \mathrm{~cm}$ steel spacer studs $40.6 \mathrm{~cm}$ apart. The deck consisted of $0.32 \mathrm{~cm}$ thick aluminum sheets over a concrete floor. The room was located within a large building, so that the effects of temperature extremes and wind were eliminated. Table 1 lists the insulations and decorative and fire protective coatings used in the full-and quarter-scale compartment fire tests and in the laboratory fire tests. The five full-scale compartment test arrangements are shown in table 2. In each of these five setups the test material covered both bulkheads and the overhead. A $30.5 \times 30.5 \mathrm{~cm}$ porous ceramic plate diffusion flame burner, selected for ease of control and convenience in testing, served as the ignition source. The burner surface was elevated $30.5 \mathrm{~cm}$ from the deck and positioned in one back corner of the compartment. The burner used methane gas and operated at a heat release rate of $62 \mathrm{~kW}$ for the first three tests with the unprotected materials. The lining materials in the remaining two tests were protected with an intumescent paint, and a more severe burner heating rate of $94 \mathrm{~kW}$ was employed to give a greater margin of safety in choosing fire barrier coatings.

Location of all instrumentation in these compartment fire tests is indicated in figure 1. The measurements which were made to characterize the thermal environment in the compartment included vertical temperature profiles down from the overhead and along the length of the doorway, vertical distribution of airflow velocities in the doorway, incident thermal radiation on the floor and, in some tests, thermal flux to the overhead and/or to the bulkhead. Auxiliary measurements to fully describe the fire included smoke obscuration, oxygen depletion, carbon monoxide and carbon dioxide concentrations of the hot gases exhausting from the upper part of the doorway. In full-scale tests (FS-3, FS-4 and FS-5) the flow near the top of the doorway was also monitored 
for the presence of hydrogen cyanide, HCN, and hydrogen chloride, HCl. Temperatures were measured with chromelalumel thermocouples made from 24 gauge wire. Heat flux to the overhead and bulkhead surfaces and the thermal radiation incident on the lower part of the room were monitored with water cooled total heat flux gauges of the Gardon type. Crumpled up newsprint on the deck was also used to indicate if and when the irradiance was sufficient to ignite such light combustible materials in the lower portion of the room. Bi-directional probes [1] 1 were employed for measuring the air velocity and the occurrence of any flow reversal along the doorway. Smoke concentration in the doorway exhaust was measured photometrically. Oxygen was sensed directly by a chemical galvanic cell. Non-dispersive infrared analyzers were used to record the concentrations of carbon monoxide and carbon dioxide. Indications of the concentrations of $\mathrm{HCN}$ and $\mathrm{HCl}$ were obtained by drawing a sample of the exhaust gases through commercial colorimetric detector tubes. Essentially, a colorimetric tube is a small-bore glass tube containing a chemical packing which changes color when exposed to a specific component of a gas mixture, and the length of the color stain is related to the concentrations of that component.

\subsection{Quarter-Scale Compartment Fires}

\subsubsection{Modeling Principles}

The air temperature in the upper part of a compartment is a good measure of its fire buildup [2]. When this air temperature reaches $500^{\circ} \mathrm{C}$, there is rapid pyrolysis and ignition of most combustible materials in the upper portion of the space. When the air temperature near the ceiling reaches about $700^{\circ} \mathrm{C}$, ignition of light combustibles can occur in the lower part of the compartment due solely to thermal radiation. A quarter-scale model having geometrically scaled room dimensions has been effective in modeling the upper compartment air temperature for the situation where the fire spreads up a combustible wall [2]. Temperature histories near the ceiling and at mid-height in the room were similar for both small-scale and full-sized room fires. The same approach has been used with some success in the modeling of fires in a simulated Navy berthing compartment [3]. In both of those modeling experiments the similarity of temperatures between the model and the prototype was maintained by having the same ratio of heat release rate to the volumetric rate of air inflow. Since the portion of the room above the doorway traps the hot combustion products from the fire and is critical to the phenomena taking place in the room, the doorway height, $h$, and consequently the lintel height were also scaled geometrically.

The air inflow, which scales as wh3/2, was controlled by changing the width of the doorway, $w$, in the model. These scaling rules are summarized as follows:

1. a) All compartment dimensions (width, length, height)

are proportional to the scale factor.

b) The height of the doorway is proportional to the scale factor.

c) The width of the doorway is proportional to the square root of the scale factor, and

d) The thickness of the materials remains the same.

2. Rate of heat release of the ignition source, fuel content and surface area of the lining material (insulation on bulkheads and overhead) are proportional to a reference area which was taken to be the floor area.

\footnotetext{
$\overline{1}_{\text {Numbers }}$ in brackets refer to the literature references 1 isted at the end of this report.
} 
3. Fire induced air supply rate is proportional to the same reference floor area.

\subsubsection{Model Experiments}

The model test enclosure was a one-quarter-scale replica of the full-scale compartment except for the doorway opening. This enclosure, shown in figure 2, consisted of a $0.64 \mathrm{~cm}$ thick aluminum alloy shell which was positioned over a $0.64 \mathrm{~cm}$ steel deck. The model enclosure having a doorway opening based on the modeling principles discussed in the preceding section was used to provide a relative evaluation of the insulations and coatings in the tests shown in table 3. The model with this doorway opening is hereafter referred to as the lintel I model. At the same time the first three full-scale compartment fire tests of foam rubber insulations and their counterpart lintel I model tests shown on table 2 were performed. It was found that the peak fire buildup in the lintel I model was considerably less than the fire growth found in two of the full-scale room fire tests of these materials.

Fire tests in the model lined with fire-exposed fibrous glass insulation, where the organic binder has burned away, indicated that the thermal radiation levels on the deck and on the bulkhead surfaces away from the ignition flame were higher than those occurring in the full-scale tests because of the relatively taller flame in the model. Thus, the differences in thermal radiation in the model and full-scale tests may not be the reason for the lower degree of fire involvement in the model. A possible reason for this divergent behavior between the full- and quarter-scale tests could be due to the unequal convective heating of the interior in the two enclosures. With turbulent flow over flat surfaces the convective heat transfer increases with the flow velocity. As the air velocities in the space vary roughly as the square root of the scale factor [2], the convective heating of the interior finish will be more severe in the prototype than in the small scale model. This is particularly important near and within the flame zone which extends upwards from the ignition source, where convective heating is the dominant mode of heat transfer to the interior finish material.

No further attempt was made to study differences in convective heating between the model and full-scale compartment fires nor to increase the convective heat transfer in the model. It was decided instead to compensate for the lower degree of fire buildup in the model by increasing the radiative environment by lowering the height of the doorway. To compensate for the reduced doorway height so as to secure the proper air inflow to the fire, the doorway must then be widened according to the flow parameter wh $3 / 2$. Fire tests in the model lined with fibrous glass insulation showed that although the peak temperatures weren't too different, the average air temperature in the upper half of the room and the thermal radiation levels in the room increased with increasing depth of the doorway lintel. Two other lintel depths of 1.4 (onequarter) and 1.8 (one-quarter) of the full-scale lintel depth, corresponding to the lintel II and III models, were then arbitrarily selected to study the effect of doorway height. The dimensions for these three openings are shown in table 4. The lintel II model was used for the test series indicated in table 5 and for the screening of most of the candidate fire barrier materials outlined in table 6 . In the modeling of the five full-scale tests with the lintel II model, the model predicted a much lower degree of fire buildup than that occurring in one of the full-scale tests. In an effort to achieve a closer simulation of prototype fire behavior the lintel III model was explored for the test arrangements shown in table 7 .

Instrumentation in the model was similar to that used in the full size compartment, except that carbon dioxide was not monitored and carbon monoxide and oxygen were measured only at the top of the doorway. Furthermore, only the air velocity near the bottom of the doorway was recorded during each model fire test. In all of the model tests, except for test 1, a gas burner positioned in one back corner, whose heat release rate was scaled to the two prototype 
rates of heat release, served as the ignition source. Test 1 was performed as a preliminary experiment to show if an oxygen-acetylene torch was suitable as an ignition source. The torch was located against the lower back corner of the compartment. The torch flame exposure was found to be too small to adequately appraise the potential fire risk of the hull insulations and was replaced by the more realistic and moderately severe exposure from the gas burner.

\subsection{Laboratory Tests of Fire Properties}

The hull insulation materials and coatings were also evaluated by laboratory fire tests for ease of ignition, surface flammability and heat release characteristics. The time at which materials contribute to a fire upon contact with flames from incidental or low energy fires was determined with the ease of ignition test [4] described in section 8.1 of the appendix. Two ASTM tests, the E 84 tunnel [5] and the E 162 radiant panel [6] tests, were employed for measuring the flame spread along materials. These tests are described in sections 8.2 and 8.3 . The rate of heat release and potential heat of these materials were measured with the rate of heat release calorimeter [7] and the potential heat test [8], discussed in sections 8.4 and 8.5 , respectively.

\section{RESULTS AND DISCUSSIONS}

\subsection{Assessment of Potential Fire Performance of Materials}

\subsubsection{Laboratory Fire Test Evaluation}

For the materials used in the compartment fire tests, the ignition, flame spread and heat release properties, as measured with the tests discussed under section 2.3, are shown in tables $8 \mathrm{~A}$ and $8 \mathrm{~B}$. In addition, for comparative purposes, other submarine interior finish materials were subjected to some of these laboratory tests. This data is given in tables $9 \mathrm{~A}$ and $9 \mathrm{~B}$. For most applications aboard a submarine, $2.5 \mathrm{~cm}$ nominal thickness insulation is used. This thickness material was employed in the ease of ignition, heat release rate calorimeter and potential heat tests. However, the flammability requirements in the Navy's material specifications call for ASTM E 84 testing of $1.3 \mathrm{~cm}$ thick specimens of the materials. Therefore specimens of both thicknesses for each of the materials used in the compartment fire tests were evaluated with the E 84 and E 162 tests.

\subsubsection{Ease of Ignition}

An earlier study [9] has suggested that materials requiring flame exposure times of less than or equal to 60 seconds for the onset of fuel contribution, using the ease of ignition test, could contribute to an early compartment flashover. The ease of ignition test results in table $8 \mathrm{~A}$ show that the fibrous glass insulations and the $\mathrm{B} 2$ and $\mathrm{C} 2$ materials having a protective coating of 0-987 or 0-9788 over primer coats of A207 had flame exposure times of greater than or equal to 60 seconds for the onset of fuel contribution. The only other material in tables $8 \mathrm{~A}$ and $9 \mathrm{~A}$ which performed well on this test was the $\mathrm{B} 2$ foam with the 0-9788 coating over the 0-634 paint. However the B2 foam with a surface coating of 0-987 alone or over a primer layer of the 0-634 reguired less than 30 seconds of flame exposure before contributing fuel to the flame. In every case where the insulation surface had only a decorative paint such as A207, D2707 or 0-634, the specimen experienced a longer time for fuel contribution than that for the unpainted material.

\subsubsection{Flame Spread}

Flame spread along a material is presently measured by the ASTM E S4 tunnel and the ASTM E 162 radiant panel. Flame propagation in the former test is in the direction of the ventilation through the tunnel. The heat and fuel generated from the burning material also flows in the same direction and 
contributes to the extension of the flame. Flame travel on the $\mathrm{E} 162$ radiant panel is downward, counter to the air updraft. Heat produced by the burning specimen moves vertically away from the specimen and does not contribute to the flame spread except for the heat that is generated locally in the vicinity of the leading edge of the flame. Both modes of fire spread occur in compartment fires. In the initial stages of a fire, the flame spread along the interior finish is upwards from the ignition flame and resembles the flame propagation along the E 84 tunnel. Downward flame propagation as well as lateral flame travel across the bulkhead and overhead, away from this initial flame zone, may be more suitably evaluated with the E 162 test. A flame spread factor and the heat contribution are independently measured in the latter test and combined to give an overall flame spread index for the material.

Navy fire performance requirements for bulkhead and overhead finish materials, as stated in MIL STD $1623 \mathrm{~B}$ [10], presently call for a maximum flame spread limit of 25 on the E 84 test. This requirement has helped to screen out some serious fire risk materials. Some Navy compartment fire tests [3] have demonstrated that a flame spread limit of 25 or less on the $\mathrm{E} 162$ test has also helped in the selection of fire safe materials. Data from the ASTM E 84 tests, given in tables $8 \mathrm{~A}$ and $9 \mathrm{~A}$, show the average as well as the range of flame spread classification (FSC) values for three tests of each submarine insulation, unless noted otherwise. Variation between tests of the same material can be large, e.g., FSC values varying from 72 to 177 and from 36 to 79 for the $2.6 \mathrm{~cm} \mathrm{~A} 6$ and $2.7 \mathrm{~cm} \mathrm{C2}$, respectively. Only the $1.3 \mathrm{~cm}$ thick B2 material had an average rating of 25 with the next best insulations, the $1.3 \mathrm{~cm}$ thick A2 and $\mathrm{C5}$, barely exceeding the acceptance limit.

Flame spread results from the E 162 test, indicated on the same tables, show a much wider range of variation for this type of material. The flame spread index, $I_{S}$, for several tests of the same material could have large variations, e.g., index values between 4 and 107 and between 62 and 1359 for the $2.7 \mathrm{~cm} \mathrm{~B} 2$ and $2.4 \mathrm{~cm} \mathrm{C4}$ insulations, respectively. The large variation in the test results of these nitrile foam materials could have also obscured the effect of surface coatings and paints. For instance, when fairly inert fibrous glass having a glass cloth surface was painted with the A207, D2707 or 0-634 coatings, higher values of $\mathrm{F}_{\mathrm{S}}$ and $\mathrm{I}_{\mathrm{S}}$ resulted. Yet $\mathrm{C} 2$ specimens painted with two of these decorative coatings showed lower $F_{S}$ and $I_{S}$ ratings than those for the unpainted samples (table 9A). The wide variations in the $\mathrm{E} 162$ evaluations of these foam materials, due to the unsteady nature of burning of such materials, make it difficult to ascertain which of these materials actually comply with the $I_{S}$ limit of 25 .

\subsubsection{Heat Release}

There is a necessity for limiting the rate of heat production from materials to help avoid a rapid fire buildup in the compartment. There is also the need to limit the total potential heat of the materials in a compartment in order to restrict the duration of the fire. The latter requirement is intended to limit the effect of the fire on the structural integrity of the compartment components as well as to reduce the probability of fire penetration into adjoining occupancies.

Rate of heat release data taken at a moderately severe fire exposure of $4 \mathrm{~W} / \mathrm{cm}^{2}$ along with the potential heat values for some submarine interior finish are indicated in tables $8 \mathrm{~B}$ and $9 \mathrm{~B}$. Most of the foam insulations had a maximum one minute average heat release rate in the vicinity of 7 to $9 \mathrm{~W}$ for each $\mathrm{cm}^{2}$ of the exposed surface area. The B2 painted with the $0-987$ had the lowest rate at $5.8 \mathrm{~W} / \mathrm{cm}^{2}$ while the $\mathrm{C} 4$ material experienced the highest value at $12.1 \mathrm{~W} / \mathrm{cm}^{2}$. For comparative purposes, the one minute average rate, at a fire exposure of $4 \mathrm{~W} / \mathrm{cm}^{2}$, for wood is about $10 \mathrm{~W} / \mathrm{cm}^{2}$ [7], and the rates for the decorative laminates, used on some bulkheads, such as $0.20 \mathrm{~mm}$ vinyl and $0.89 \mathrm{~mm}$ melamine are about 3.3 and $5.5 \mathrm{~W} / \mathrm{cm}^{2}$, respectively [9]. Laboratory heat release rate data is often difficult to relate to a compartment fire involving the interior 
finish. A material's rate of heat generation can be a strong function of the radiant exposure history. The interior surfaces in a room would generally be exposed to a non-uniform fire exposure throughout the space, and portions of the room surface could be in various stages of fire involvement. In addition, the rate of heat production in the room is a function of the fire affected area, which in turn depends on the rate of surface flame spread. To avoid a serious fire risk situation some limitation should be put on the heat generation rate, as measured with the laboratory rate of heat release calorimeter, in conjunction with restrictions on the time to fuel contribution from the ignition test and the flame spread rating of the material.

Potential heat test results for several representative submarine insulations are given in tables 8B and 9B. On a weight basis, the potential heat of these materials is about the same as wood. Expressed in terms of the exposed surface area, these low density materials have values of 43 to $76 \mathrm{MJ} / \mathrm{m}^{2}$ as compared with, e.g., 7 and $24 \mathrm{MJ} / \mathrm{m}^{2}$ for the $0.20 \mathrm{~mm}$ vinyl and $0.89 \mathrm{~mm} \mathrm{mela-}$ mine laminates, respectively. A commonly used relation between fire severity and fire load [11] shows that for every $12 \mathrm{~kg}$ of wood equivalent load per $\mathrm{m}^{2}$ of deck area increase in fire load, or $240 \mathrm{MJ}$ per $\mathrm{m}^{2}$ of deck area, the fire severity, in terms of ASTM E 119 type of fire exposure, increases by $1 / 4$ hour.

\subsubsection{Quarter-Scale Compartment Fire Testing}

A summary of the tests with the model enclosure is presented in tables 3 , 5, 6 and 7. The first test of the series demonstrated that an oxygen acetylene torch, positioned in one back corner of the model, would only char or burn away the foam insulation around the flame impingement zone; also, compartment temperatures did not exceed $100^{\circ} \mathrm{C}$ over a ten-minute test period. Subsequent tests used a gas burner having an output of either 3.9 or $5.9 \mathrm{~kW}$, corresponding to 62 and $94 \mathrm{~kW}$ in the counterpart full size tests, respectively, as the ignition source. The thermal contribution of the ignition source represents only a small part of the heat generation rate known to result in flashover conditions in the compartment. Flashover experiments in full and quarter size rooms with an opened doorway have demonstrated that roughly $650 \mathrm{~kW}$ and $340 \mathrm{~kW}$ were necessary to have flashover in a well insulated $3.0 \times 3.0 \times 2.3 \mathrm{~m}$ high space at times of 0.75 and 5.0 minutes, respectively [12]. Therefore, the low and high ignition sources would supply only about 10 and $15 \%$, respectively, of the rate of heat release needed to attain flashover in a short duration fire and approximately 18 and 28\%, respectively, for flashover in the vicinity of five minutes. Consequently, flashover will not occur if the compartment space interior walls and/or additional combustible contents do not supply the additional energy release.

Compartment and doorway air temperatures are given for each model test. Compartment air temperatures were occasionally affected by the localized heating of the thermocouple, while the doorway air temperature was more representative of the average overhead compartment air temperatures.

\subsubsection{Evaluation of Unprotected Hull Insulation}

Fire tests of the unprotected materials with the model having the lintel I doorway are given on table 3. A comparison of the doorway air temperatures in the table disclosed that the model fires with the unpainted insulations $\mathrm{C} 2$ and B2 behaved much like the fire test with the fairly inert fibrous glass when the low ignition setting was used. At the high ignition exposure the model fire with the $C 2$ again performed similarly to the test having the fibrous glass, but model experiments with the unpainted B2 and A2, tests 19 and 20, led to flashover of the space after 1.2 and 1.4 minutes following ignition. Test 3 indicated that a decorative paint over an inert surface did not increase the fire buildup. However, decorative paints over the nitrile foams C2 and B2 increased the surface flaming to the extent where flashover occurred in seven of the eight cases where these foams were painted. In another model fire where the insulation was J2 foam painted with A207 flashover also occurred. 
Fire tests with the quarter-scale compartment having the lintel II doorway are outlined in table 5. Model fire test 22 was similar to tests 4 and 5 in table 3 except for a 7\% lowering and 1l\% widening of the doorway. While only doorway air temperatures of about $215^{\circ} \mathrm{C}$ were found in tests 4 and 5 , air temperatures of almost $600^{\circ} \mathrm{C}$ were measured in the doorway of test 22. Even when the heat release rate of the ignition source in tests 4 and 5 was increased by $40 \%$, as in tests 16 and 17 in table 3, doorway temperatures increased to only $240^{\circ} \mathrm{C}$. For the $\mathrm{C} 2$ insulation the lowering of the doorway by $7 \%$ had a much greater effect on the fire than a significant increase in the size of the fire initiation source.

As part of the test series with the model having the lintel II doorway, acoustical fibrous glass, chloroprene-laminated nitrile foam, spackled cork and chlorinated alkyd paint over fibrous glass were evaluated under the high ignition setting. The model having the acoustical glass experienced doorway temperatures of less than $80^{\circ} \mathrm{C}$ above that found for the fire with the unpainted fibrous glass. Chlorinated alkyd paint had little effect on the test results. The test with the spackled cork lasted 3.4 minutes before flashover occurred. The chloroprene-nitrile foam performed well for seven minutes, at which time the fire accelerated to flashover by eight minutes. This chloroprene, however, is not suitable for submarine finish because of its open cell structure, which could absorb fuel in the event of a nearby oil leak and then act as a wick if ignited.

Model fire tests in the compartment with the lintel III doorway are given in table 7. Tests 33 and 34 were similar to the tests 4 or 5 and test 10 in table 3, respectively, except for the doorway dimensions. In tests 33 and 34 , the doorway was lowered by $14 \%$, and both tests experienced flashover.

A brief summary of the modeling experiments with the quarter-scale compartments having the three doorway lintel heights for the unpainted B2 and C2 nitrile foam materials is given in table 10. The data show that for tests of these materials, small decreases in doorway height led to relatively large increases in compartment interior and doorway air temperatures. Lowering the doorway can sometimes have a greater effect on the fire buildup than a fairly large increase in the size of the fire initiation source.

\subsubsection{Evaluation of Some Fire Protective Coatings}

Candidate fire barrier materials used in this study are shown in table 6 . The coatings that helped prevent flashover of the compartments with either the lintel II or the lintel III doorway and an interior finish of C2 or B2 foam, under the high ignition source setting, were the following:

$$
\begin{aligned}
& \text { 1. } 0-987 \text { with and without primer coats of A207 } \\
& \text { 2. } 0-9788 \text { with an undercoating of } 0-634 \\
& \text { 3. } 0-330 \text { latex with an undercoating of } 0-634 \\
& \text { 4. } \text { Z-3300 }
\end{aligned}
$$

In tests $38,45,46$ and $47,0-987$ was applied over primer coats of A207 to simulate the application on existing submarines where decorative paints had been used. 0-987 over bare C2 and B2 insulations, tests 37 and 44, and over primer coats of A207, offered at least ten minutes of protection against compartment flashover. However, when the protective layer is too thin, e.g., about $0.018 \mathrm{~cm}$ thick as in test 34 , the degree of fire protection is compromised. Even when only the compartment lining along the upper half of the bulkhead and the overhead is covered with a $0.025 \mathrm{~cm}$ thick coating of $0-987$, as in test 47 , a full ten minutes protection still resulted. 
The 0-9788 coating is identical to the 987 formulation except for the addition of a fungicide. Occasionally there is a problem with poor surface adhesion with both of these coatings unless a suitable primer paint is used. In test 50, the B2 foam was coated with just the 0-9788. Within a few seconds following introduction of the ignition flame, the fire barrier paint on the overhead began to flake off, resulting in a flashover at about four minutes. Test 51 was protected with the 0-987 and survived the test duration of ten minutes without reaching flashover. The application of a primer coat of 0-634 before coating with the 9788 paint, as in test 48 , helped alleviate the problem of the latter paint separating from the overhead. The compatibility of chlorinated alkyd over the 0-9788 coating with the 0-634 primer was evaluated in test 49. At 15 seconds into the test, large sections of the alkyd paint started to peel and fall from the overhead.

The remaining two candidate coatings, which were effective in preventing flashover over the ten minute test duration, had other drawbacks. The 0-330 latex cracked easily and chipped off when it was handled. The Z-3300 was too rigid to tolerate much vibration and separated readily from the foam when the latter insulation was slightly flexed several times.

\subsubsection{Generation of Combustion Gases}

Since some of these insulation materials are organic chlorine- and nitrogen-containing compounds, the principal toxic combustion products are presumed to be $\mathrm{CO}, \mathrm{HCN}$ and $\mathrm{HCl}$. Other combustion products may be formed and toxicological screening tests using animals may be necessary to avoid the introduction of super-toxicants. Concentrations of HCN, HCl and CO in the hot combustion gases exhausting from near the top of the doorway were measured in some of the quarter-scale fire tests of insulations with and without fire protective coatings. This data is presented in table 11 . In test 31 with the painted spackled cork, flashover occurred, and concentrations of $\mathrm{CO}$ and $\mathrm{HCN}$ were measured at $2.0 \%$ and $100 \mathrm{ppm}$ at five minutes, respectively. Where flashover occurred and the interior finish was a nitrile foam, tests $23,33,34$, and 50 in table 11, relatively high concentrations of both $\mathrm{HCN}$ and $\mathrm{CO}$ were found for both bare and painted foams. In these four tests the co levels averaged $3.0 \%$ and the HCN concentrations reached $600 \mathrm{ppm}$ or higher. Where there were lower $\mathrm{CO}$ concentrations, HCN levels were also lower, but not proportionately so. In the five cases in table 11 where $40 \mathrm{ppm} H C N$ were measured, the concentrations of $\mathrm{CO}$ averaged $0.6 \%$. For the eleven cases involving the foam insulations and where $5 \mathrm{ppm}$ or less of $\mathrm{HCN}$ were found, the levels of $\mathrm{CO}$ averaged $0.2 \%$.

Concentrations of $\mathrm{HCN}$ and $\mathrm{HCl}$ were estimated with colorimetric indicator tubes. This detection technique gives only an approximation and is affected by elevated temperatures and moisture in the sampling line. HCl analysis with the tubes has the added disadvantage in that indication of the gas can be upset by the presence of the oxides of nitrogen. When the concentrations of No and $\mathrm{NO}_{2}$ are higher than that for $\mathrm{HCl}$, there may be no indication of the $\mathrm{HCl}$ using this method. In all of the model tests shown in table 11 , only test 34 with the unpainted B2 foam resulted in measurable HC1 concentrations above 200 ppm.

It is apparent from the data given in table 11 that if flashover can be prevented, the generation of the combustion gases $\mathrm{HCN}, \mathrm{HCl}$ and $\mathrm{CO}$ will be minimized. The paints in table 11, by themselves, did not appear to contribute significantly to the production of these gases. On the contrary, the fire resistive coatings reduced the generation of combustion products by preventing full fire involvement of the space.

\subsubsection{Relationship between Laboratory Fire Tests and Compartment Fire Tests}

No single small-scale laboratory test can fully determine the fire hazard of materials. Each of these tests can only indicate one or more components of 
the fire risk potential of materials. The discussion in section 3.1 .1 .1 concerning the results from the ease of ignition tests suggested that the unprotected foams may pose a serious fire risk potential. The ignition data also suggested that the B2 insulation having a protective coating of 0-987 over primer coats of A207 was acceptable. These findings were consistent with the full-scale compartment fire test results shown in table 2 for the same materials. However, B2 coated with the 0-987 without the primer failed the ignition requirement and yet performed well in the full-scale compartment fire test.

As for flame spread ratings discussed in section 3.1 .1 .2 , the unpainted B2 insulation satisfies the present NavY ASTM E 84 requirements for a fire safe material. Yet the compartment fire test of this same foam insulation, test FS-3 in table 2, indicated that it was a potentially serious fire risk material. The A2 foam barely exceeded the "safe" flame spread limit of 25 on the ASTM E 84 test; yet model test 20 in table 3, which was lined with this insulation, experienced flashover in a little over a minute. Data from the ASTM E 162 tests, shown on tables $8 \mathrm{~A}$ and $9 \mathrm{~A}$, indicated that the unpainted C2, C7 and C8 foam insulations had averaged ratings of about 25, implying low fire risk materials. These ratings for materials are difficult to relate to the materials' behavior in compartment-type fires. The large variation existing between the ASTM E 162 tests of the same material introduces even more uncertainty to the interpretation of these ratings. The $\mathrm{C} 7$ and $\mathrm{C} 8$ materials were not tested in a compartment, but the full-scale test FS-2 of the C2 foam demonstrated that it was a potentially fire hazardous insulation. These findings demonstrated that flame spread ratings by themselves are not capable of screening out potentially high fire risk interior finish. This conclusion is confirmed by room fire studies conducted at Underwriters Laboratories [13] where little correlation was found between the flame spread ratings for some interior finish and the degree of fire buildup in a $2.4 \times 3.7 \times 2.4 \mathrm{~m}$ high room. Their test compartment was lined with plastic board materials and a burning 20-pound wood crib, positioned in one corner, served as the ignition source. These tests demonstrated that fires with some plastic interior finish having a 25 or lower rating on either or both of the E 84 and E 162 tests still led to flashover of the compartment.

The potential heat and rate of heat release data for materials are also difficult to relate to compartment fire tests of the materials. Usually materials which have a high rate of heat release will contribute more to the fire buildup. Materials with a high potential heat will result in a longer duration fire. Presently these two fire properties can be used to eliminate only those materials having significantly higher potential heat and rate of heat release values than the rest of the candidate materials. For the submarine foam insulations the potential heats only varied between 4 to $6 \mathrm{~kJ} / \mathrm{cm}^{2}$, and no single material stood out as being much worse than the rest. A review of the rate of heat release data in tables $8 \mathrm{~B}$ and $9 \mathrm{~B}$ showed that these foam insulations had maximum one-minute rates which varied from 6.6 to $12.1 \mathrm{w} / \mathrm{cm}^{2}$ with no one material being significantly worse than the others.

\subsection{Comparison of Full- and Quarter-Scale Compartment Fires}

\subsubsection{Fire Buildup}

Doorway and interior air temperatures and flashover times for the five full-scale tests and their corresponding model tests are presented in table 2. Whenever a newsprint flashover indicator on the deck ignited during a test, flashover was assumed to have occurred. Ignition of the newsprint or some designated minimum doorway or interior air temperatures are only rough indicators of flashover because of the variation in the thermal and physical properties of crumpled newsprint, the non-uniform distribution of temperatures throughout the compartment, and the differences between tests of the combined thermal radiation from the smoke, the hot air and the heated surfaces. The hot air inside the compartment usually became well mixed by the time it exhausted through the doorway. Consequently, doorway temperatures may be more reliable 
flashover indicators than the interior air temperatures. In every case where an ignition of the newsprint indicator had occurred, room and doorway temperatures either had attained or continued to increase to at least $650^{\circ} \mathrm{C}$ and $550^{\circ} \mathrm{C}$, respectively. In comparing model and prototype results only broad categories of fire involvement should be considered. For example, the fire buildup could be described as low, moderate, or extensive, corresponding to doorway temperatures of less than $250^{\circ} \mathrm{C}$, between $250^{\circ} \mathrm{C}$ and $450^{\circ} \mathrm{C}$, and above $450^{\circ} \mathrm{C}$.

The model fires in tests 4 and 10, employing the lintel I doorway, failed to achieve the same degree of fire buildup as that found for their counterpart full-scale tests, FS-2 and FS-3. Whereby the latter two fires attained flashover, the model fires reached doorway air temperatures of only about $200^{\circ} \mathrm{C}$. The peak fire development in the model fires with the lintel II doorway, tests $22,23,44$ and 46, simulated the fire buildup in their counterpart full size tests reasonably well. However, test 24 , with this lintel II doorway, did not result in flashover, which occurred in its corresponding full-scale test FS-3. The fire buildup in the quarter-scale tests, 33, 34 and 51, having the lintel III doorway, was in reasonable agreement with the degree of fire involvement observed in their corresponding prototype fires. Figure 3 shows the doorway air temperature variation with time for the model tests having the lintel III doorway and for their counterpart full size fires. The model fires developed slower, but the peak fire buildup, as evidenced by the occurrence of flashover or by the maximum air temperature, simulated the full-scale behavior.

A condensed version of table 2, showing a comparison of the fire buildup in the full- and quarter-scale compartment fires, is given in table 12 .

\subsubsection{Supporting Measurements}

\subsubsection{Thermal Fluxes}

Flux measurements at the time of peak doorway temperature for the full-scale and corresponding quarter-scale tests are indicated in table 13. The average irradiance on the deck at which flashover occurred was $2.2 \mathrm{~W} / \mathrm{cm}^{2}$ for the full-scale fires FS-1, FS-2, and FS-3, and $2.4 \mathrm{~W} / \mathrm{cm}^{2}$ for the model fires 23, 33 and 34. Irradiance levels on the deck for tests FS-4 and FS-5 were also lower than those in their counterpart model tests. This was also observed in tests where the interior finish was an inert fibrous glass insulation [12]. The higher flux probably resulted from the relatively taller burner flames in the model and from the relatively larger heated surface area in the model which occurred as a consequence of the lowered lintel.

\subsubsection{Interior and Doorway Air Temperature Distributions}

The vertical air temperature profiles inside the compartment and along the doorway for three prototype fires, at their respective times of peak air temperature as measured at a location $10.2 \mathrm{~cm}$ below the doorway lintel, are shown in figures 4 and 5. Superimposed on the figures are the corresponding test data from the model tests 33,34 and 51 with the lintel III doorway. The times to reach the peak doorway air temperature for tests FS-2, 33 and 34 also corresponded to the times for flashover, whereas flashover occurred seconds after the peak doorway air temperature was attained in test FS-3. In the model tests 33 and 34, temperatures were lower than in the prototype; and consequently, the model fires required a longer fire exposure of the insulation in order to reach flashover. For model test 51 and its corresponding prototype fire FS-4, the fire was confined principally to the zone in contact with the flames from the ignition source, producing only a moderate air temperature rise. The vertical distribution of temperatures below the center of the overhead indicated much higher temperatures in the model than those in the prototype fire. However, these temperature differences in the upper part of the compartment did not show up in the doorway temperature profiles. This may be explained by the relatively taller flame heights in the model. The higher flames could have 
resulted in a more intense localized heating of the strand of thermocouples in the upper region of the compartment. However, the heated air in the compartment space became well stirred by the time it reached the doorway. This is evident from the similarity in the doorway temperature profiles for the two tests.

\subsubsection{Air Velocity and Mass Balance across Doorway}

Full-scale velocity data along the doorway centerline were available only for FS-1, FS-2 and FS-4, and these are shown in figures 6 and 7 . For a quick fire development leading to flashover, such as those occurring in tests FS-1 and FS-2 and their counterpart model fires, doorway velocities change rapidly. Initially there is a rapid expansion of the compartment air, similar to a low order explosion, which results from the sudden surge in the temperatures in the space. Air inflow is, at first, very low but there is a high rate of hot air exhausting from the compartment. Mass balances based on velocity measurements across the doorway for these compartment fires are presented in table 14. For FS-1 and FS-2 and during the first 15 to 20 seconds of test FS-4 the flow out of the compartment greatly exceeded the airflow entering the space. From the temperature variation with time inside the compartment for tests FS-1 and FS-2, the excess of the mass flow out over that flow into the space was estimated to be approximately $20 \mathrm{~kg} / \mathrm{min}$ over the time interval from 0.13 to $0.50 \mathrm{minutes}$. This compares with the value of about $40 \mathrm{~kg} / \mathrm{min}$ calculated from the velocity measurement in the doorway. Non-uniform distribution of the flow across the width of the doorway, together with thermal radiation errors in temperature measurement, could have accounted for this discrepancy in estimating the mass flow leaving the compartment. In test FS-4, where only a slow and moderate fire buildup occurred, there was a rough balance of the flow entering and leaving the compartment at times longer than 20 seconds.

A comparison of model and prototype velocities is almost impossible during the highly transient fire phenomena taking place in tests FS-1 and FS-2. However, the data from FS-4 can be compared with the velocities from the quarter-scale tests 44 and 51. Scaling principles indicate that velocity should vary with the square root of the scale factor [2], meaning that the prototype velocities should be twice as large as the model velocities. This scaling of velocity has been experimentally verified for fires performed in the one-quarter-scale compartment lined with fibrous glass [12]. Table 15 shows that the velocity ratio of the full-scale data to the model values is roughly about two.

\subsubsection{Combustion Products}

Measurements of carbon monoxide, carbon dioxide, oxygen depletion, hydrogen cyanide, hydrogen chloride along with the smoke production data for the prototype and counterpart model compartment fires are indicated in tables 16 and 17. The $\mathrm{CO}$ and $\mathrm{O}_{2}$ data shown in table 16 indicate that the $\mathrm{CO}$ concentrations measured near or at flashover were higher and the $\mathrm{O}_{2}$ levels were lower in the prototype tests than those for the model fires. This was a direct consequence of the more intense fire development in the full-scale fires at the time of flashover. Even though the temperatures for FS-2, FS-3 and their corresponding model fires, shown in figures 4 and 5 , clearly showed a more intense fire buildup in the prototype fires near or at flashover, model tests can still be used to roughly predict full-scale behavior. For example, the quarter-scale tests gave high $\mathrm{CO}$ and low $\mathrm{O}_{2}$ levels when their counterpart prototype tests did so. The concentrations of $\mathrm{CO}$ and the oxygen depletion, measured along the upper half of the doorway and given in table 16, are also presented in figures 8 and 9 .

An interesting observation is that the carbon monoxide and oxygen depletion profiles in the full-scale tests which experienced flashover did not look like their temperature profiles in the upper half of the doorways as shown 
in figure 5. As for the generation of $\mathrm{HCN}$ and $\mathrm{HCl}$, the data in table 17 show that the concentrations of these gases roughly followed the generation of $\mathrm{CO}$ in both of the model and full size fires.

Smoke measurements from both model and prototype fires, presented in table 16, indicate that smoke concentrations were a magnitude higher for the tests where flashover occurred than the smoke levels in the tests where only a moderate fire buildup was found. Smoke levels in the quarter-scale tests, expressed as an optical density per meter of smoke path length, were about twice as high as those in the full size fires.

\section{CONCLUSIONS}

1. The PVC nitrile rubber foams tested provide a potentially serious fire hazard when used unprotected as hull insulation in submarines. This is particularly true because of the rapidity of the fire buildup once these materials become involved. Flashover occurred in less than one minute in the full-scale compartment tests of these materials.

2. Two intumescent paints (0-987 and 0-9788) were identified, which if applied in sufficient thickness (at least $0.025 \mathrm{~cm}$ ), would provide at least ten minutes delay time before the onset of flashover. These paints met the elasticity requirements for the above application. These coatings greatly reduced the overall generation of carbon monoxide, hydrogen cyanide, hydrogen chloride, and smoke in the compartment fires by preventing much of the foam surface from being involved in the fire.

3. The present criterion based just on the flame spread ratings from the ASTM E 84 tunnel test does not adequately reflect the fire hazard of these materials. Ignition, flame spread, heat release and smoke generation characteristics of the material are all important in determining its potential fire hazard.

4. At the present time there is no demonstrated method of eliminating the full-scale compartment fire test for determining the suitability of an interior finish material for shipboard and submarine application.

5. The quarter-scale model test is useful as an economical screening tool for evaluating a large number of materials. It offers advantages similar to the full-scale test in that for any given fire initiation source, the ignition, flame spread, heat release and smoke generation characteristics of the interior finish, along with the complex effects of the thermal reinforcement on these properties as the fire grows, are all automatically included. The final approval of materials should, however, at this stage, be based on the results of a full-scale test.

6. A modification of the scaling rules with regard to the height of the room above the top of the doorway was preliminarily examined during this project. It was found that better agreement could be obtained between the full-scale and the quarter-scale tests if the doorway height was reduced by $14 \%$ in the model.

\section{RECOMMENDATIONS}

1. There is a need to evaluate the fire behavior of these insulations under a more realistic compartment configuration such as the proposed test room shown on figure 10. The interior of a submarine has frame bays or ribs every 0.6 to $0.9 \mathrm{~m}$ apart. Each rib is perpendicular to and protrudes 20 to $25 \mathrm{~cm}$ from the steel hull and extends around the inside perimeter of the submarine. The effect of these frame bays on the fire is uncertain. They could act as fire stops, inhibiting the lateral spread of the fire, 
or they could channel the fire to the overhead, and intensify the local fire involvement to the point where subsequent fire spread accelerates. Currently, the Navy has an ongoing program at the National Bureau of Standards to study the effect of these frame bays on compartment fire buildup.

2. Further effort by the Navy to adopt the present quarter size room fire test for general shipboard interior finish is recommended. Although the model test in its present state can be used to screen submarine hull insulation materials, more research on the type and size of the fire initiation source is necessary before the test can be adopted for the more general needs of the Navy. The ignition source used to evaluate materials must be consistent with their intended use. For example, the desired fire initiation exposure for assessing the potential fire risk of shipboard interior finish may be quite different from that for screening the components of building construction. Furthermore, the testing of overhead finish used on surface ships, for example, might require an ignition source having a higher rate of heat generation than that needed for evaluating bulkhead sheathing to adequately screen such materials.

\section{ACKNOWLEDGMENTS}

Appreciation is expressed to Mr. Charles Veirtz, who built the test compartments and performed the actual testing, and to Mr. W. J. Parker for his helpful comments throughout the project.

This study was supported by the Naval Sea Systems Command, Department of the Navy, under the direction of Mr. Dallas Whitehurst.

\section{REFERENCES}

[1] McCaffrey, B. J. and Heskestad, G., A robust bi-directional low-velocity probe for flame and fire application, Combustion and Flame, Vol. 26, $125-127$ (1976).

[2] Parker, W. J. and Lee, B. T., A small-scale enclosure for characterizing the fire buildup potential of a room, Nat. Bur. Stand. (U.S.), NBSIR 75-710 (June 1975).

[3] Lee, B. T. and Parker, W. J., Naval shipboard fire risk criteria-berthing compartment fire study and fire performance guidelines, Nat. Bur. Stand. (U.S.), NBSIR 76-1052 (July 1976).

[4] Lawson, J. R. and Parker, W. J., Development of an ease of ignition test using flame impingement, Nat. Bur. Stand. (U.S.), NBSIR, to be published.

[5] Standard Method of Test for Surface Burning Characteristics of Building Materials, ASTM E 84-70, American Society for Testing and Materials.

[6] Robertson, A. F., Gross, D. and Loftus, J. J., A method for measuring surface flammability of materials using a radiant energy source, Proceedings of the American Society for Testing and Materials, Vol. 56, 1437-1452 (1956).

[7] Parker, W. J. and Long, M. E., Development of a heat release rate calorimeter at NBS, ignition, heat release and noncombustibility of materials, ASTM STP 502, American Society for Testing and Materials, 135-151 (1972). 
[8] Loftus, J. J., Gross, D. and Robertson, A. F., Potential heat--a method for measuring the heat release of materials in building fires, Proceedings of the American Society for Testing and Materials, Vol. 6l, 1336-1348 (196].).

[9] Lee, B. T. and Parker, W. J., Fire buildup in shipboard compartments-characterization of some vulnerable spaces and the status of prediction analysis, Nat. Bur. Stand. (U.S.), NBSIR 79-1714 (1979).

[10] Fire Performance Requirements and Approved Specifications for Interior Finish Materials and Furnishings (Naval Shipboard Use), Military Standard 1623 B (SHIPS) (Nov. 14, 1975).

[11] Building Materials and Structures, NBS Report BMS 92 (Oct. 7, 1942).

[12] Lee, B. T., Quarter-scale modeling of room fire tests of interior finish, Nat. Bur. Stand. (U.S.), NBSIR, to be published.

[13] Castino, G. T., et al., Flammability studies of cellular plastics and other building materials used for interior finish, Underwriters Laboratories, Inc. (1975).

[14] Gross, D., Loftus, J. J. and Robertson, A. F., Method for measuring smoke from burning materials, ASTM Special Technical Publication No. 422, 164-204 (1967), American Society for Testing and Materials, Philadelphia, $\mathrm{Pa}$. 


\section{APPENDIX - LABORATORY FIRE TESTS}

\subsection{Ease of Ignition}

The ease-of-ignition test [4] measures the flame exposure time required for the onset of fuel contribution of materials. Two specimens $14.0 \mathrm{~cm}$ $(5-1 / 2 \mathrm{in})$ wide and $15.2 \mathrm{~cm}$ (6 in) high face each other $50 \mathrm{~mm}$ (2 in) apart. A methane diffusion flame passes between the specimen surfaces and extends about $25.4 \mathrm{~cm}(10 \mathrm{in})$ above them. By subjecting up to six pairs of specimens to different exposure times the minimum flame exposure time required to produce a contribution of fuel from the specimen is determined.

\subsection{ASTM E 84* Flame Spread}

The ASTM E 84 tunnel test [5] measures the flame spread performance of the specimen material relative to that of asbestos-cement board and red oak flooring under similar test conditions for a duration of ten minutes. A $50.8 \mathrm{~cm}$ (20 in) wide and $7.3 \mathrm{~m}(24 \mathrm{ft})$ long specimen is horizontally-mounted in an overhead orientation in a $7.6 \mathrm{~m}(25 \mathrm{ft})$ long test chamber. The fire end of the tunnel is provided with two gas burners delivering flames upward against the surface of the test sample. An air intake port $7.6 \mathrm{~cm}$ ( 3 in) high measured from the floor level of the test chamber is provided at the fire end. The vent end is fitted to a $40.6 \mathrm{~cm}$ (16 in) diameter flue pipe. Changes in smoke density in the latter is monitored photometrically. A thermocouple is also mounted $2.5 \mathrm{~cm}$ (l in) from the sample surface, $30.5 \mathrm{~cm}$ (1 ft) from the vent end.

Results are given for flame spread, fuel contributed and smoke developed. These values, obtained from burning the test material, represent a comparison with those of asbestos-cement board expressed as zero and red oak flooring expressed as 100. Flame spread classification, FSC, is determined as follows:

(1) For materials on which flame spreads $5.9 \mathrm{~m}(19-1 / 2 \mathrm{ft})$ in a time, $t$, of 5-1/2 min, or less, FSC $=550 / \mathrm{t}$.

(2) If the flame front spreads $5.9 \mathrm{~m}(19-1 / 2 \mathrm{ft})$ in more than $5-1 / 2 \mathrm{~min}$, then $\mathrm{FSC}=50+275 / \mathrm{t}$.

(3) For materials on which the flame spreads less than $5.9 \mathrm{~m}$ $(19-1 / 2 \mathrm{ft})$ but more than $4.1 \mathrm{~m}(13-1 / 2 \mathrm{ft}), \mathrm{FSC}=50+4.6 \mathrm{~d}$ where $\mathrm{d}$ is in meters, and FSC $=50+1.4 \mathrm{~d}$ where $\mathrm{d}$ is in feet.

(4) When the extreme flame spread distance is $4.1 \mathrm{~m}$ (13-1/2 ft) or less, the classification is $\mathrm{FSC}=16.8 \mathrm{~d}$ for $\mathrm{d}$ in meters and $5.1 \mathrm{~d}$ for $d$ in feet.

The value for fuel contributed is derived by calculating the net area under the time-temperature curve from the thermocouple near the vent end for the test material and comparing this area with the net area under the curve for untreated red oak flooring.

The smoke developed during the test is determined from the time dependent increase in obscuration of a light source due to the smoke in the vent pipe. The smoke rating is derived by calculating the net area under the timeobscuration curve for the test material and comparing this area with the net area under the curve for untreated red oak flooring.

\footnotetext{
*A new method has been adopted for calculating the flame spread, but the above method was used for the materials tested on this project.
} 


\subsection{ASTM E 162 Flame Spread}

The ASTM E 162 radiant panel test [6] requires a $15 \times 46 \mathrm{~cm}(6 \times 18$ in) specimen, facing and inclined 30 degrees to a vertically-mounted, gas-fired radiant panel. The energy output of the panel is controlled to be the same as that from a blackbody of the same dimensions operating at a temperature of $670^{\circ} \mathrm{C}\left(1238^{\circ} \mathrm{F}\right)$. Ignition is caused by a pilot flame just above the upper edge of the test specimen and observations are made of the progress of the flame front down the specimen surface, as well as the temperature rise of the thermocouples in a stack supported above the test specimen. The test is terminated when the flame reaches the end of the specimen or in 15 minutes, whichever time is less. The flame spread index, Is' is computed as the product of the flame spread factor, $F_{S}$, and the heat evolution, $Q_{S}$, or $I_{S}=F_{S} Q_{S}$, where

$F_{S}=1+\frac{1}{t_{3}}+\frac{1}{t_{6}-t_{3}}+\frac{1}{t_{9}-t_{6}}+\frac{1}{t_{12}-t_{9}}+\frac{1}{t_{15}-t_{12}}$ and $Q_{S}=0.1 \Delta T / B$

The symbols $t_{3}$ to $t_{15}$ to correspond to times in minutes from specimen exposure until arrival of the flame front at a position 7.6 to $38 \mathrm{~cm}$ ( 3 to 15 in), respectively, along the length of the specimen. The value of 0.1 in the relation for the heat evolution is a constant arbitrarily chosen to yield a flame spread index of approximately 100 for red oak. The quantity $\Delta \mathrm{T}$ is the observed maximum stack thermocouple temperature rise over that observed with an asbestos-cement board specimen, and $B$ is the maximum stack thermocouple temperature rise for unit heat input rate to the calibration burner.

This test procedure has been adopted as an ASTM standard method for measuring the flammability of building materials. The flame spread index value is zero for asbestos-cement board and 100 for red oak flooring.

\subsection{Rate of Heat Release Calorimeter}

The heat release rate calorimeter [7] measures the rate of heat generation for materials exposed to radiant fluxes up to $10 \mathrm{~W} / \mathrm{cm}^{2}\left(8.8 \mathrm{Btu} / \mathrm{s} / \mathrm{ft}^{2}\right)$ with a response time of a few seconds. A 11.4 by $15.2 \mathrm{~cm}(4-1 / 2 \times 6$ in) specimen, up to $2.5 \mathrm{~cm}$ ( $1 \mathrm{in}$ ) in thickness, is oriented vertically in front of gas-fired radiant panels lining three sides of a combustion chamber. The radiation comes from the surface of these panels where temperatures may be varied between $627^{\circ} \mathrm{C}$ and $1027^{\circ} \mathrm{C}\left(1160^{\circ} \mathrm{F}\right.$ and $\left.1880^{\circ} \mathrm{F}\right)$ to produce the desired irradiance level on the sample. The edges of the specimen are shielded by an insulated holder. Air for combustion of the sample passes up through the porous floor of the chamber.

The fast time response of the calorimeter to the heat leaving the front surface of the specimen is achieved by maintaining the instrument at a constant temperature, thus overcoming the thermal inertia associated with the heating and cooling of the calorimeter walls. The constant temperature operation is accomplished with an auxiliary burner whose fuel supply is regulated by an automatic temperature controller. An increase in heat due to the burning of the specimen is then compensated by a decrease in the fuel flow rate to the burner. The measured decrease in the rate of flow of the fuel is then recorded as the rate of heat release of the specimen.

\subsection{Potential Heat Test}

The potential heat test [8] provides a quantitative measure of the total heat release under typical fire exposure conditions without regard to the rate at which the heat is released.

The heat of combustion, $Q_{r}$ ! of sample of the material, measured by an oxygen bomb calorimeter, after it has been exposed to a "standardized fire" 
(two hours in a muffle furnace at $750^{\circ} \mathrm{C}\left(1382^{\circ} \mathrm{F}\right.$ )) is compared with the heat of combustion $Q_{m}$ of an unexposed sample. The potential heat $Q_{t}$, is given by

$$
Q_{t}=Q_{m}-R Q_{r}
$$

where $\mathrm{R}$ is the fractional weight remaining after the exposure.

Determinations may be made on simple materials, or on composite assemblies of materials from which a representative sample can be taken and pulverized into a homogeneous mixture. 

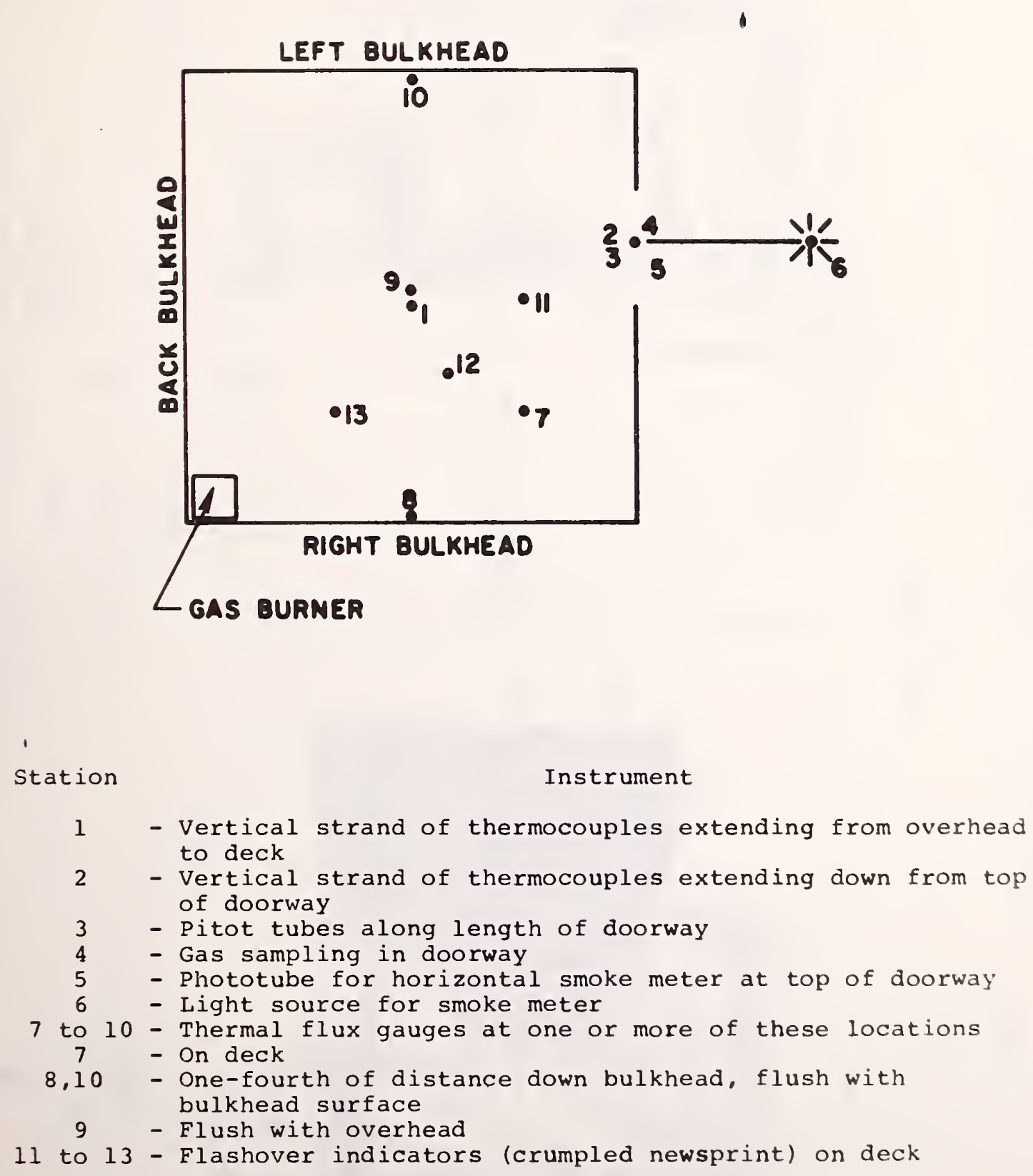

1 - Vertical strand of thermocouples extending from overhead to deck

2 - Vertical strand of thermocouples extending down from top of doorway

3 - Pitot tubes along length of doorway

4 - Gas sampling in doorway

5 - Phototube for horizontal smoke meter at top of doorway

6 - Light source for smoke meter

7 to 10 - Thermal flux gauges at one or more of these locations

7 - On deck

8,10 - One-fourth of distance down bulkhead, flush with bulkhead surface

9 - Flush with overhead

11 to 13 - Flashover indicators (crumpled newsprint) on deck

Figure 1. Plan view of compartment arrangement showing locations of ignition burner and instrumentation 


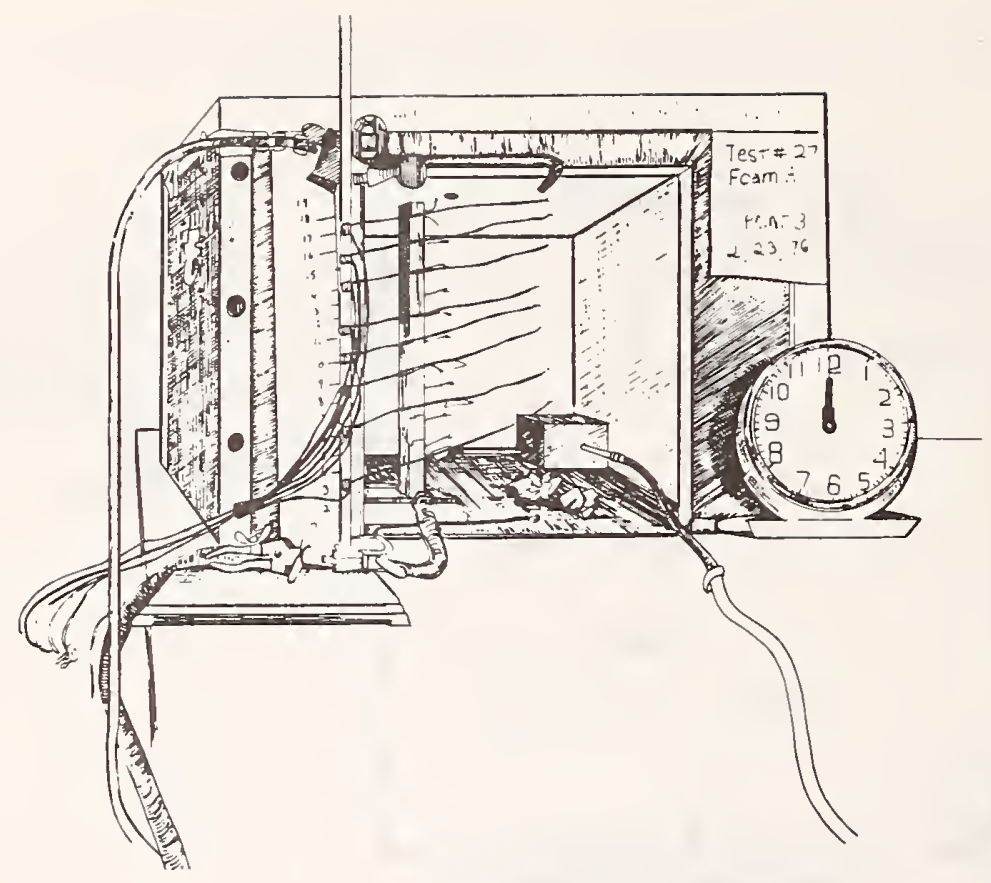

Figure 2A. Quarter-scale compartment fire test prior to ignition

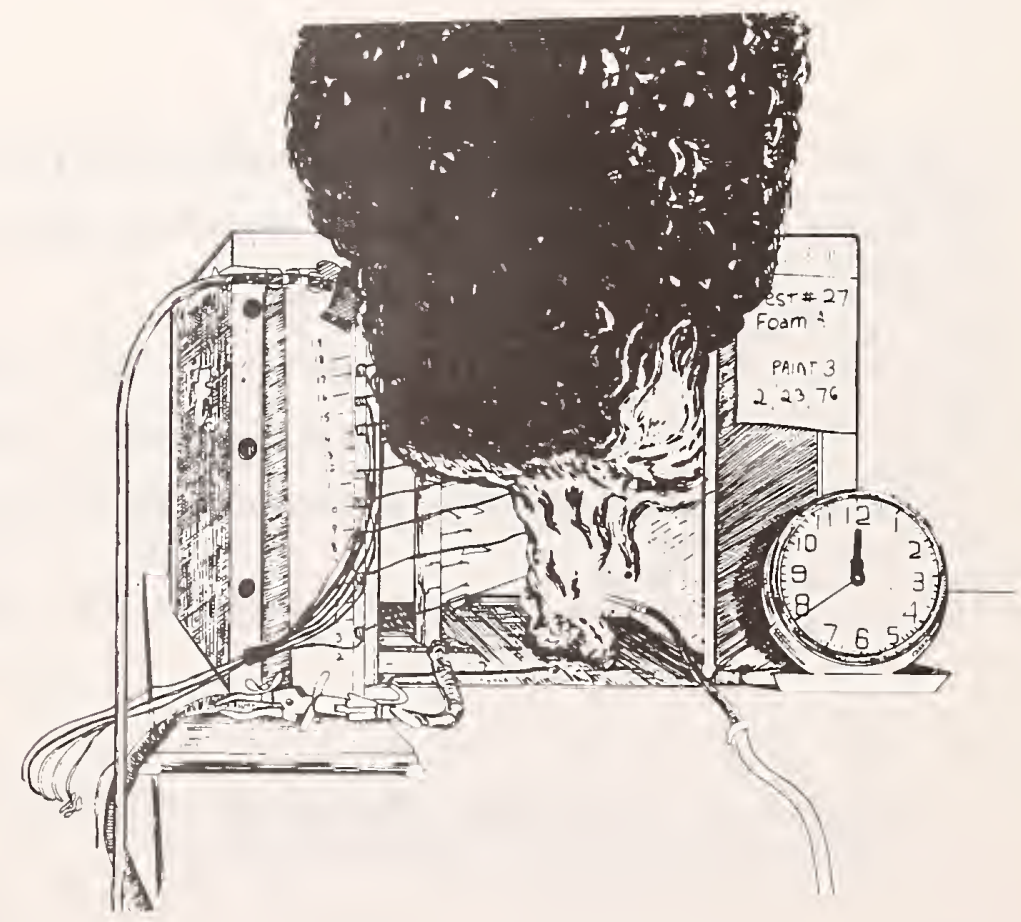

Figure 2B. Quarter-scale compartment fire test at flashover 


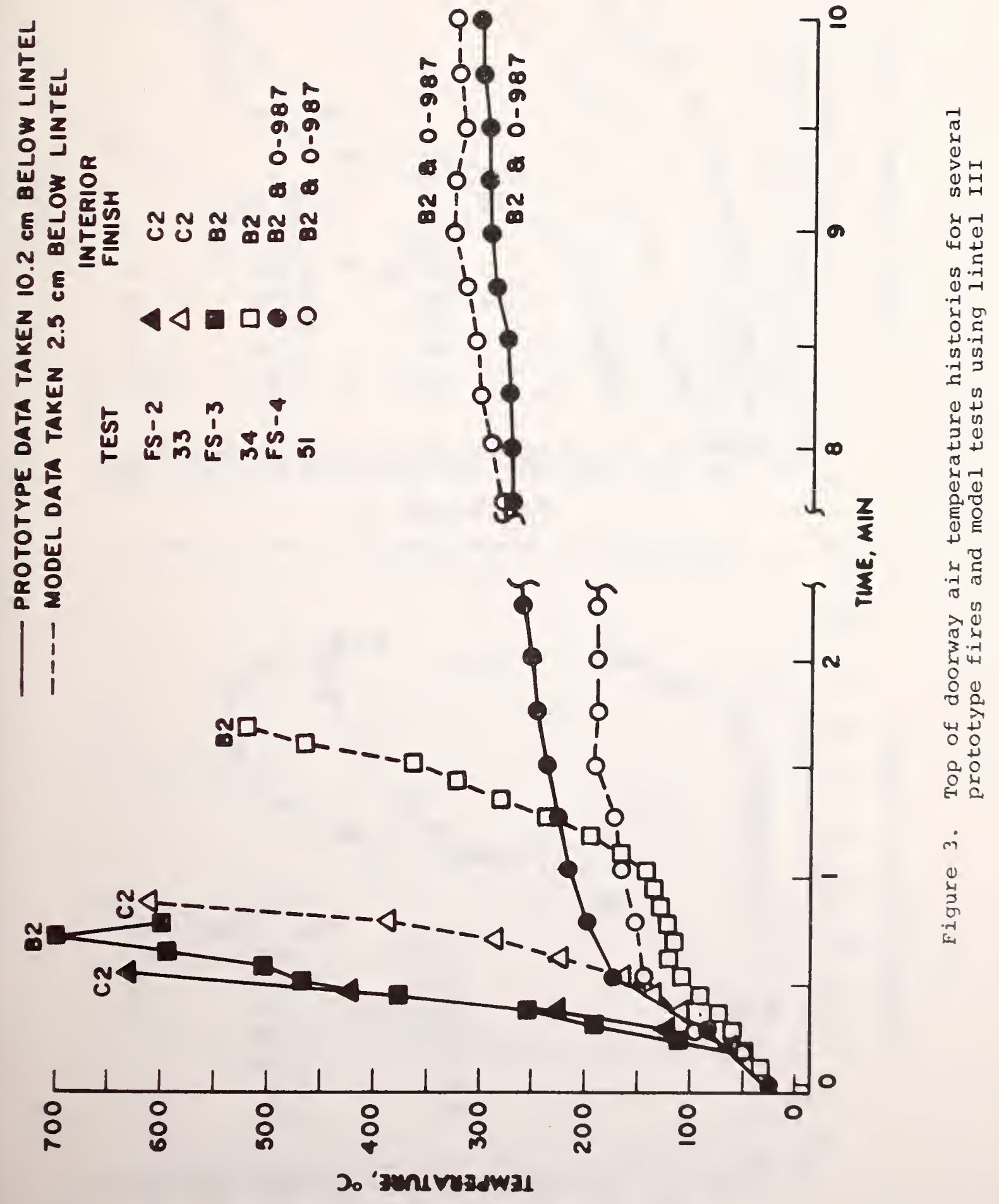




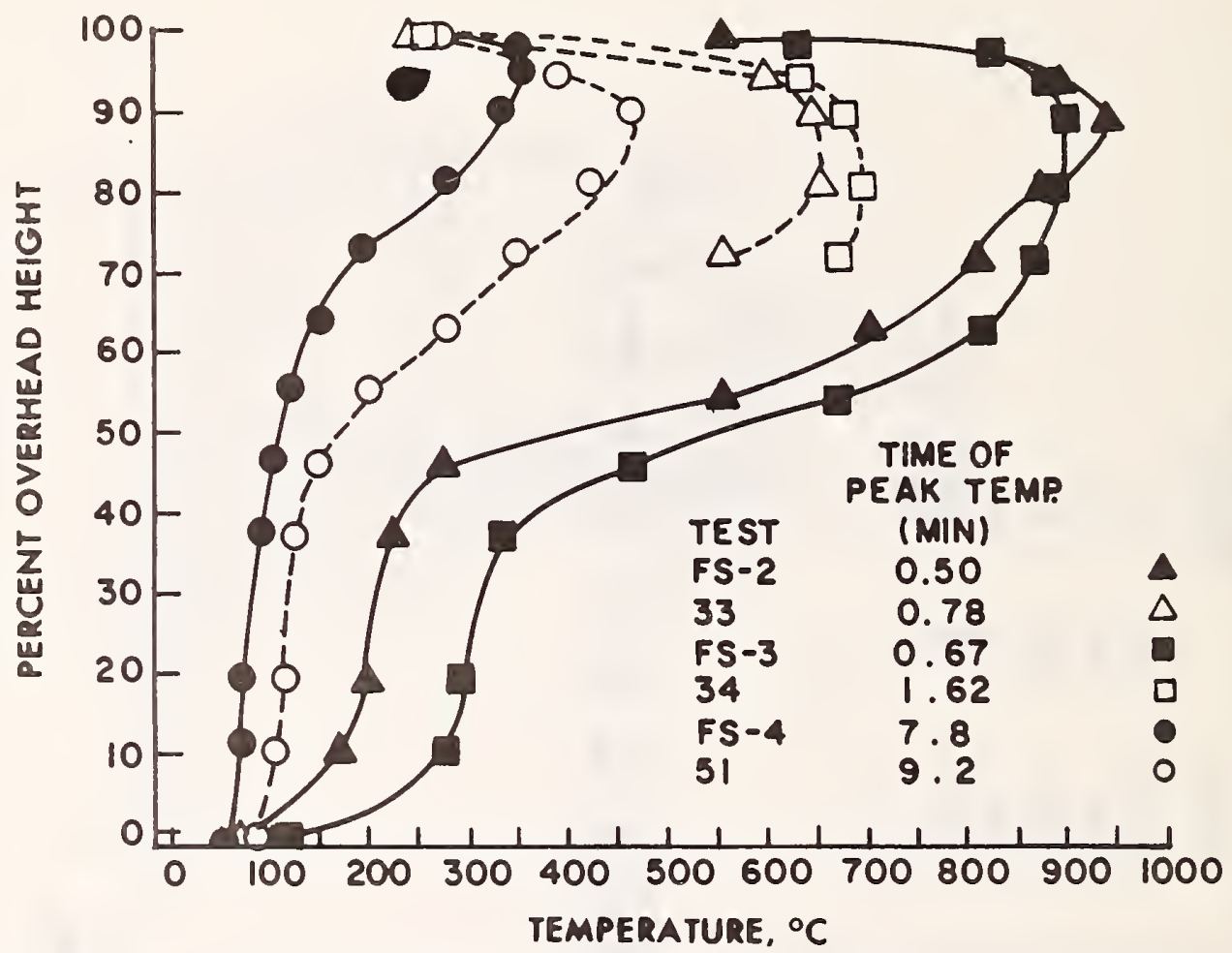

Figure 4. Compartment air temperature profiles at time of peak doorway air temperature

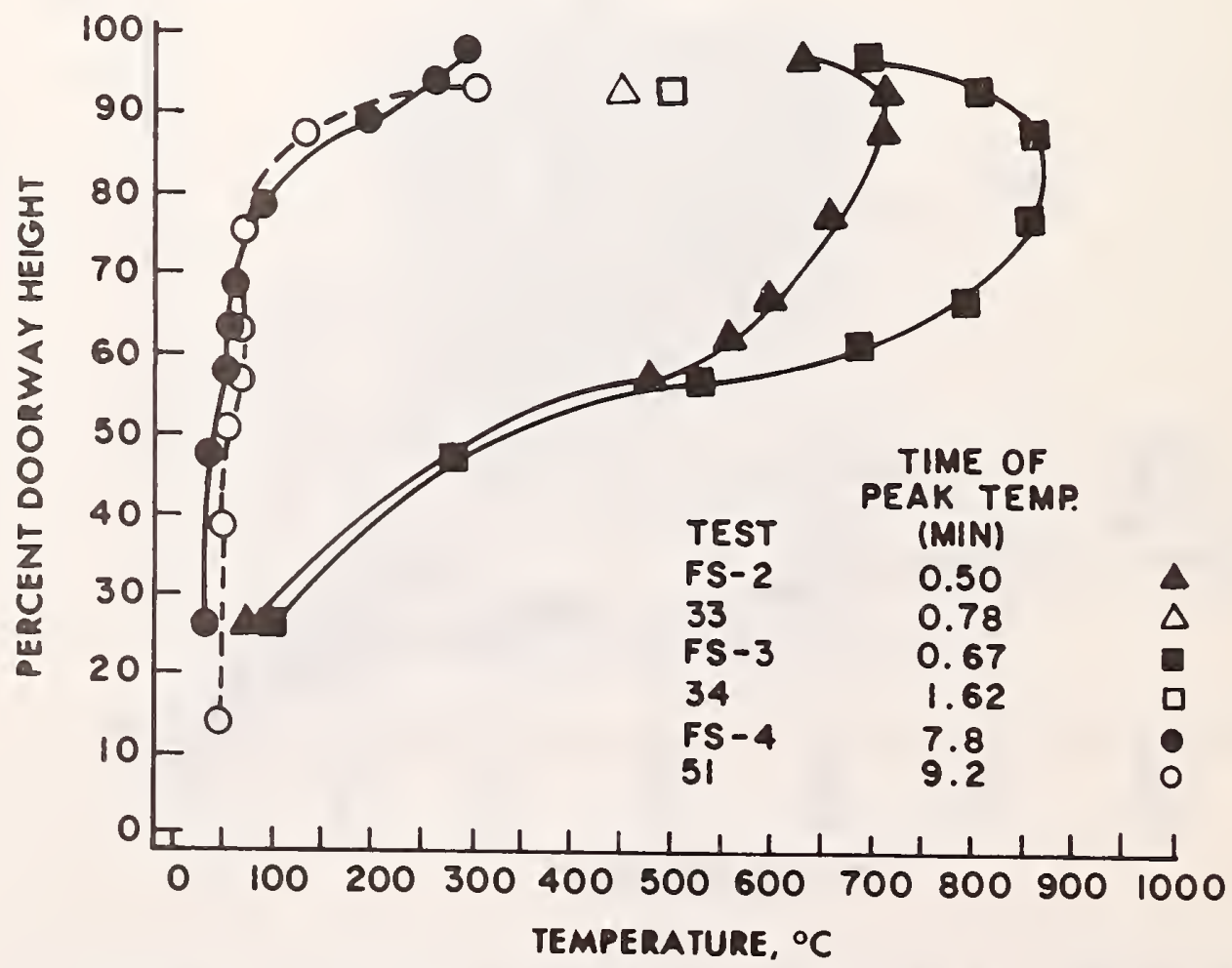

Figure 5. Doorway air temperature profiles at time of peak doorway air temperature 


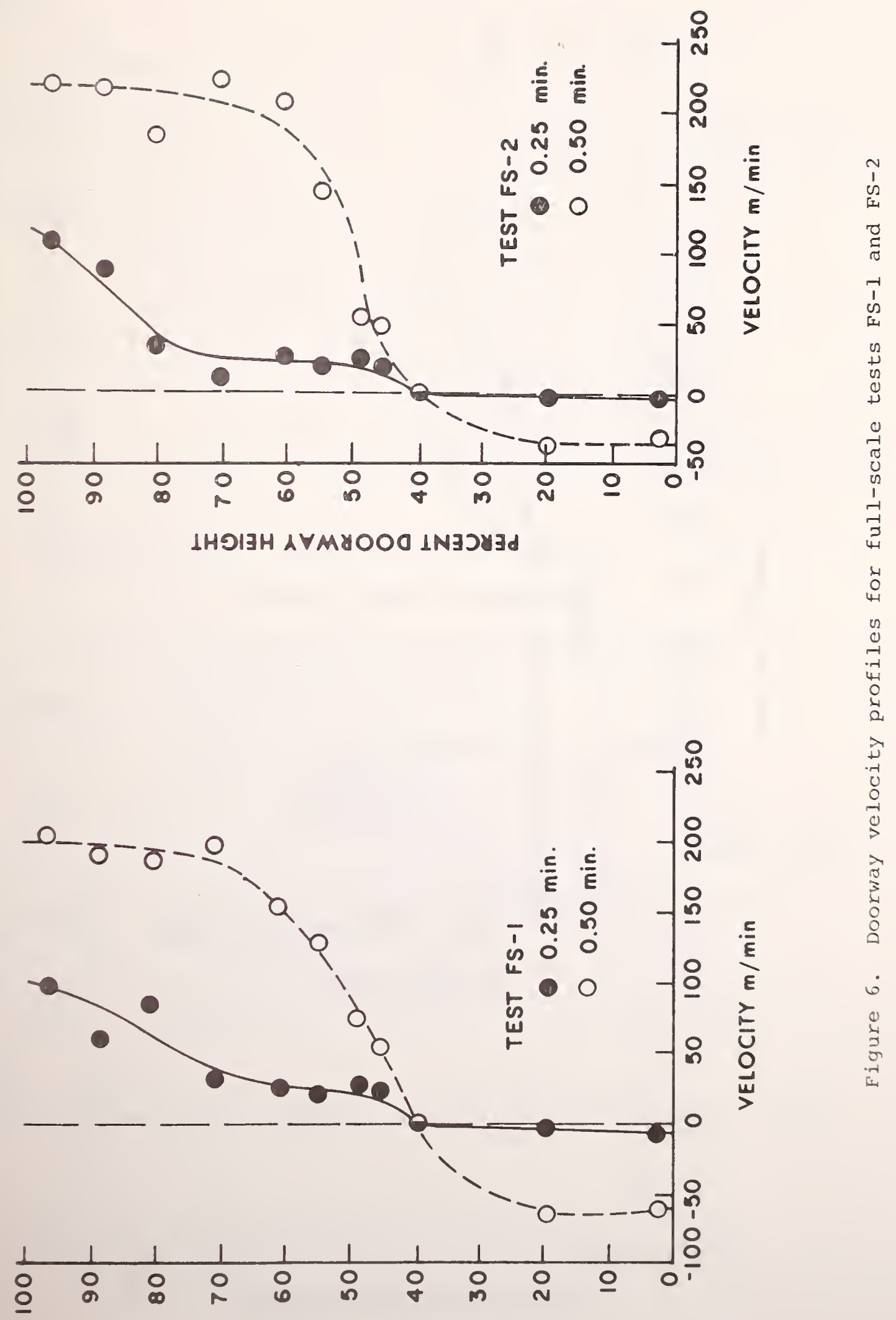

ІНУЗН АУMYOOO INJכY3d 


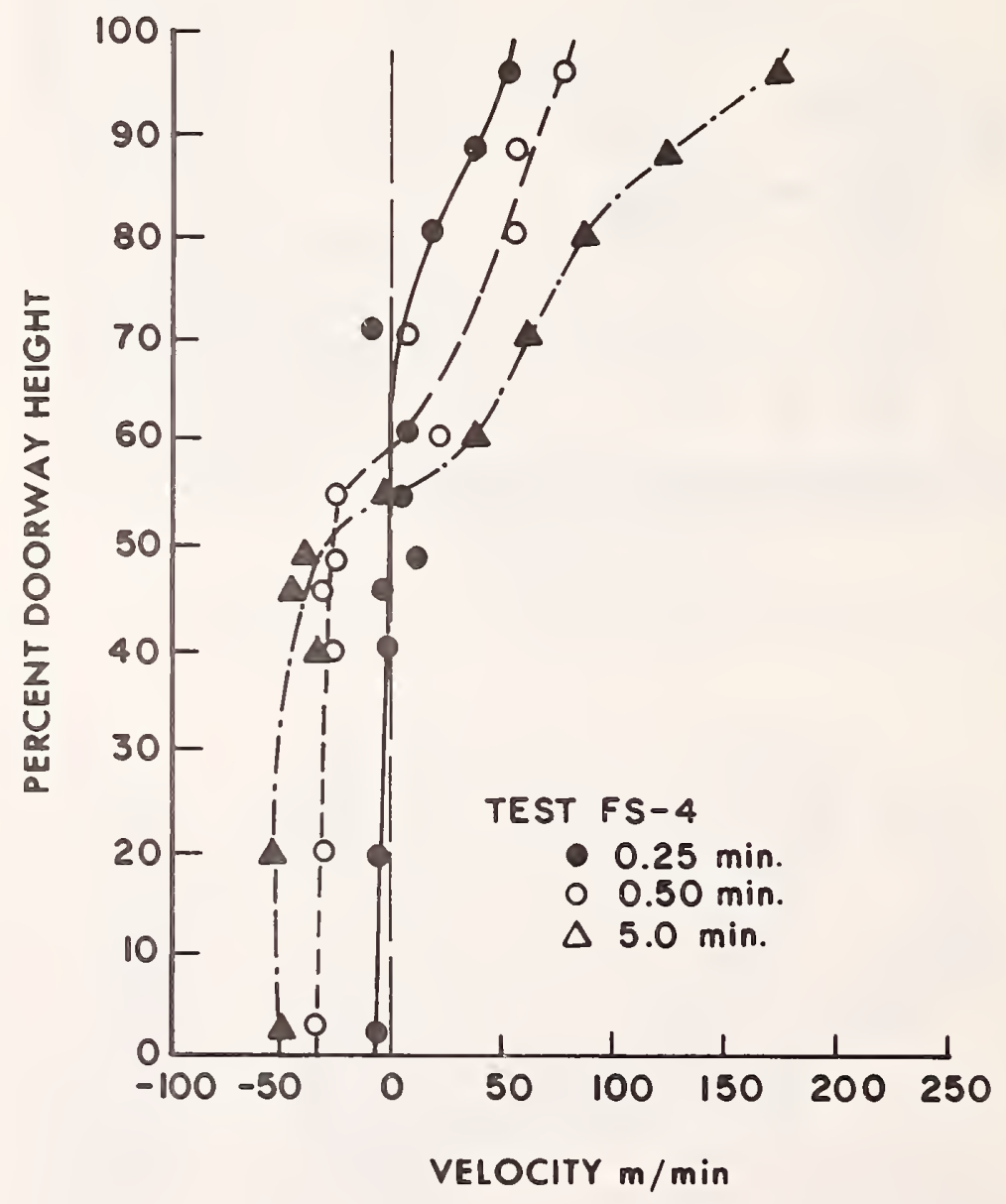

Figure 7. Doorway velocity profiles for full-scale test FS-4 


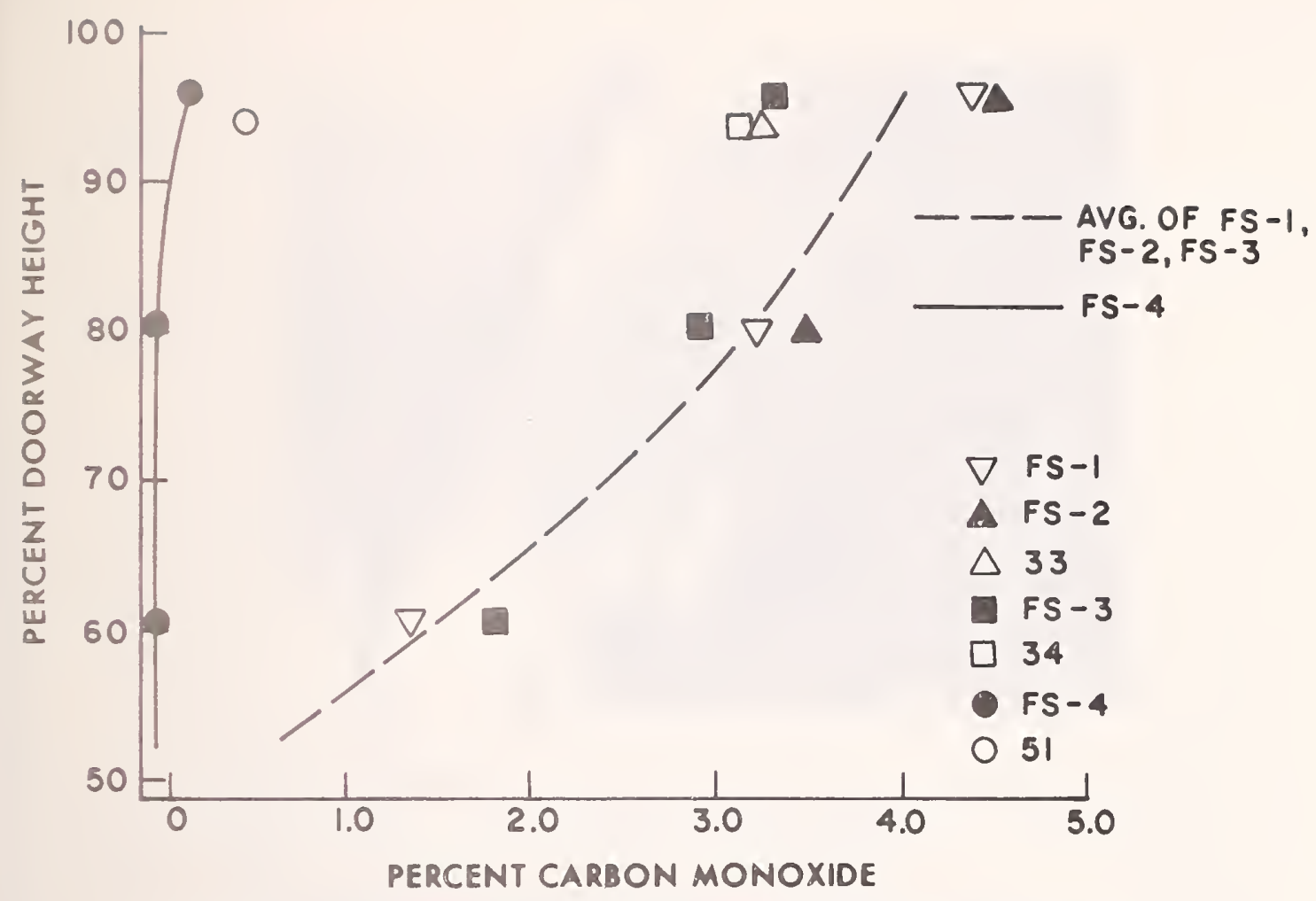

Figure 8. Carbon monoxide concentrations along doorway at time of peak doorway air temperature

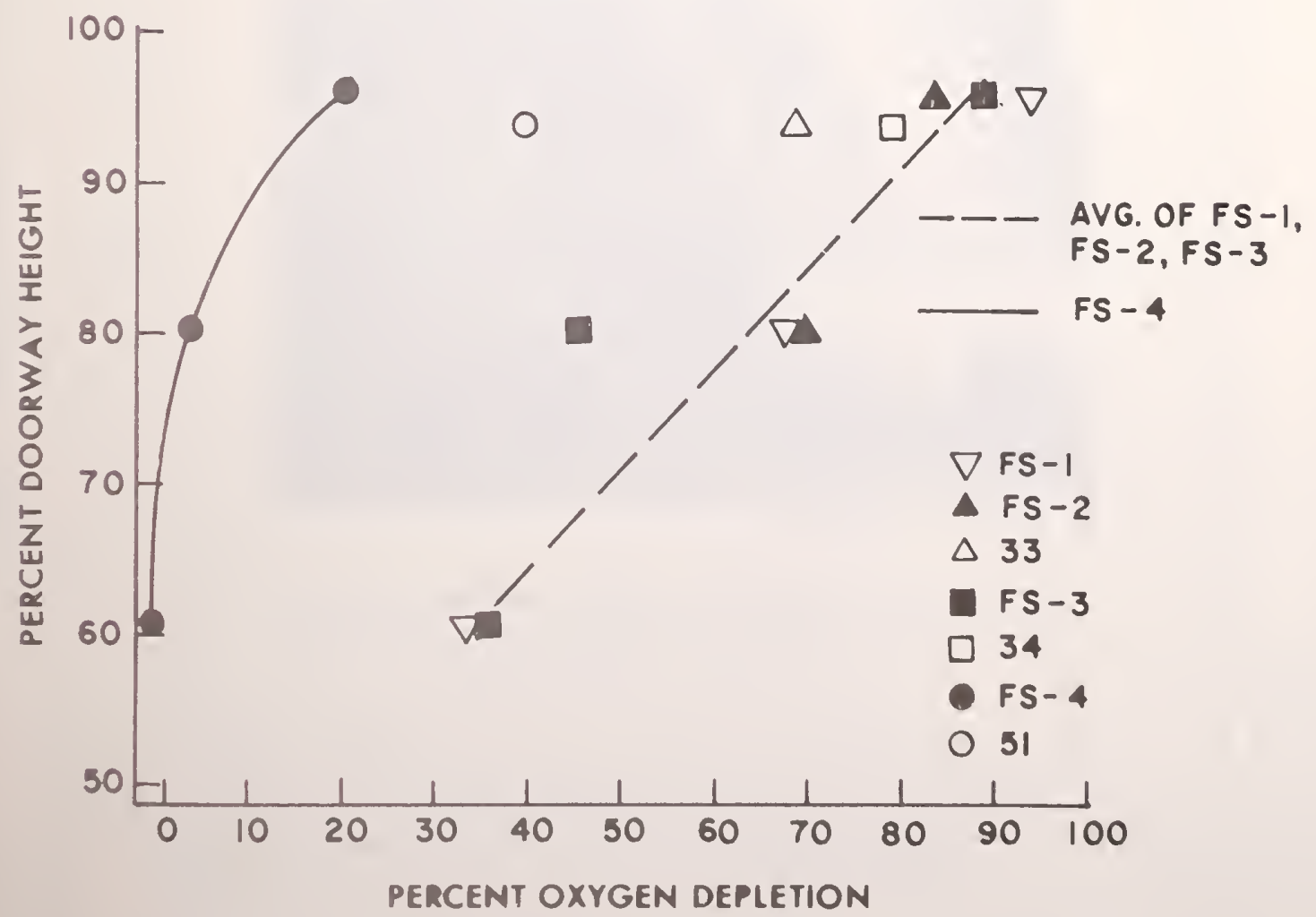

Figure 9. Oxygen depletion profile along doorway at time of peak doorway air temperature 


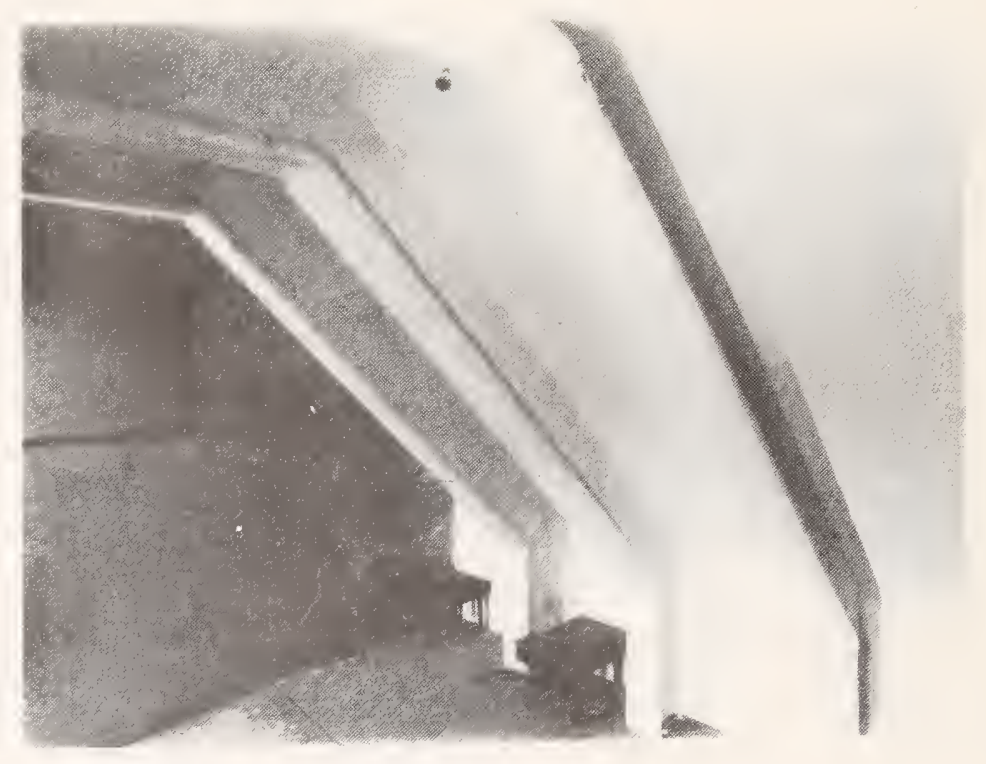

Compartment showing gas burners in back corner and in one frame bay

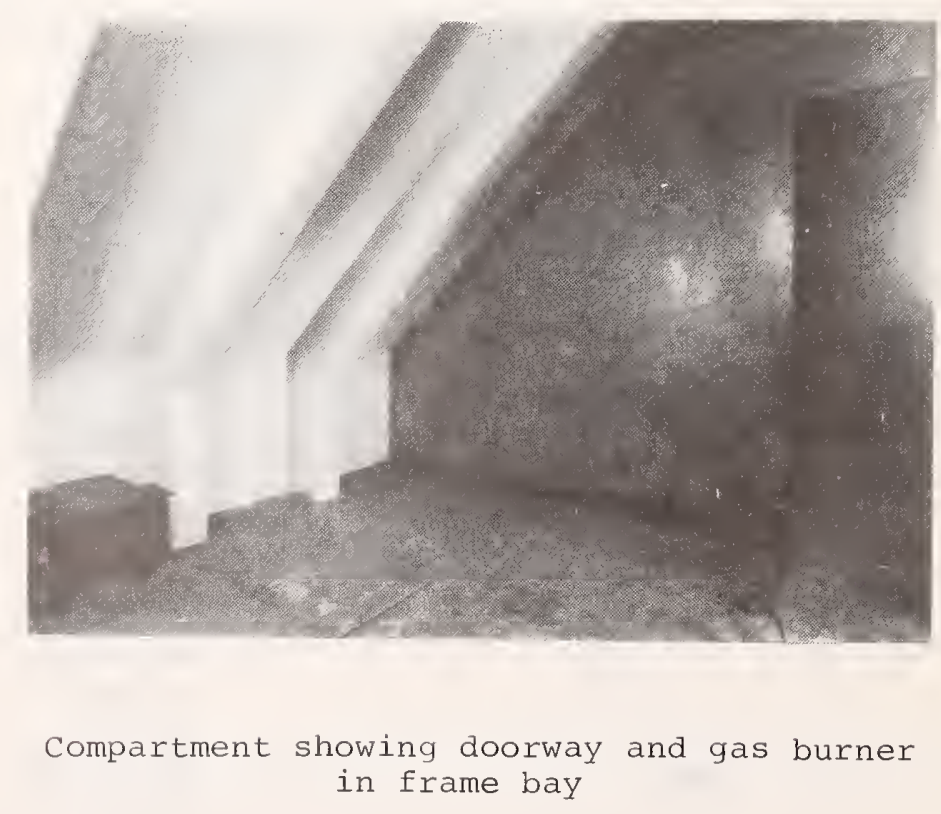

Figure 10. Proposed submarine fire test compartment with frame bays 


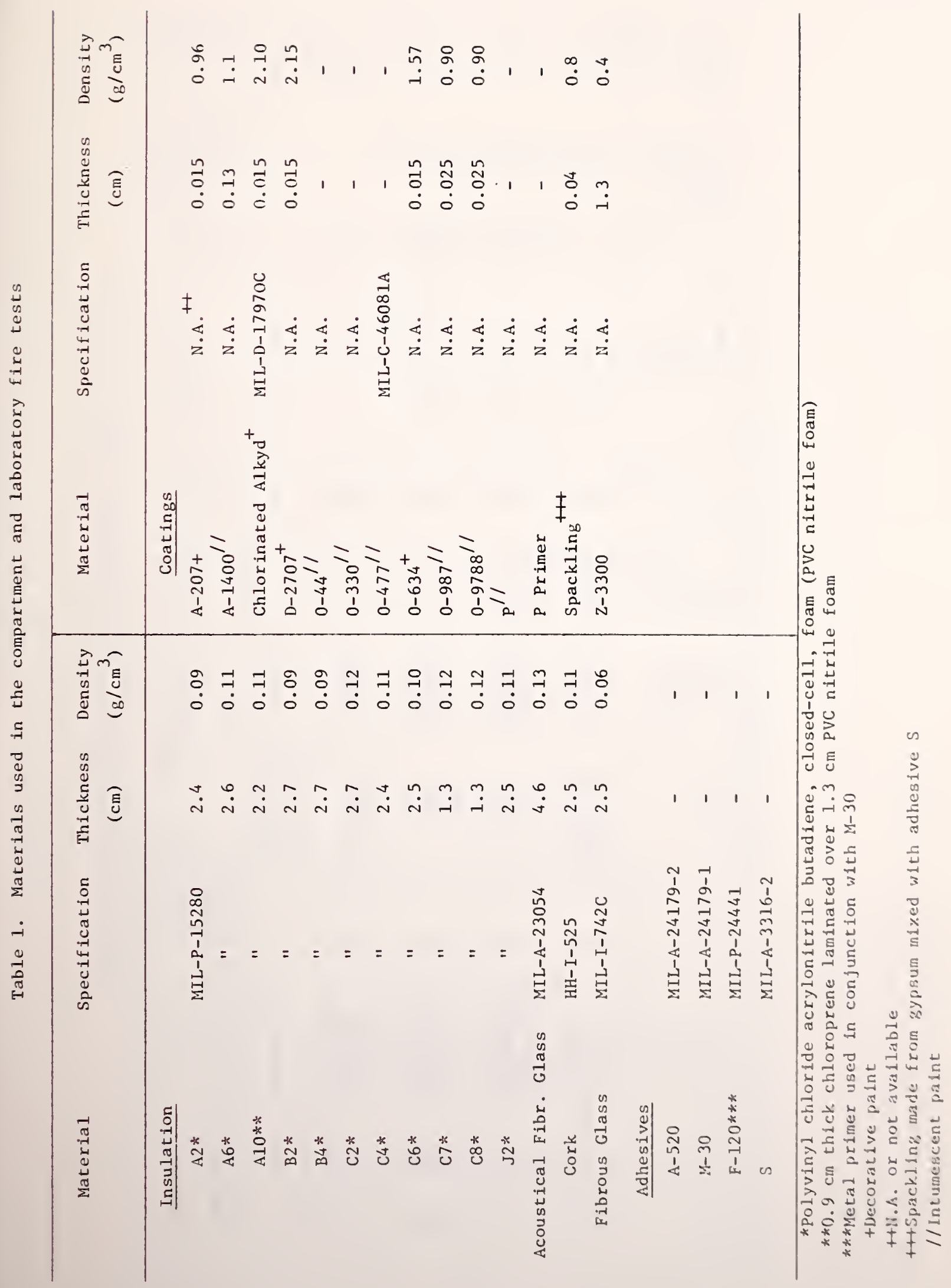




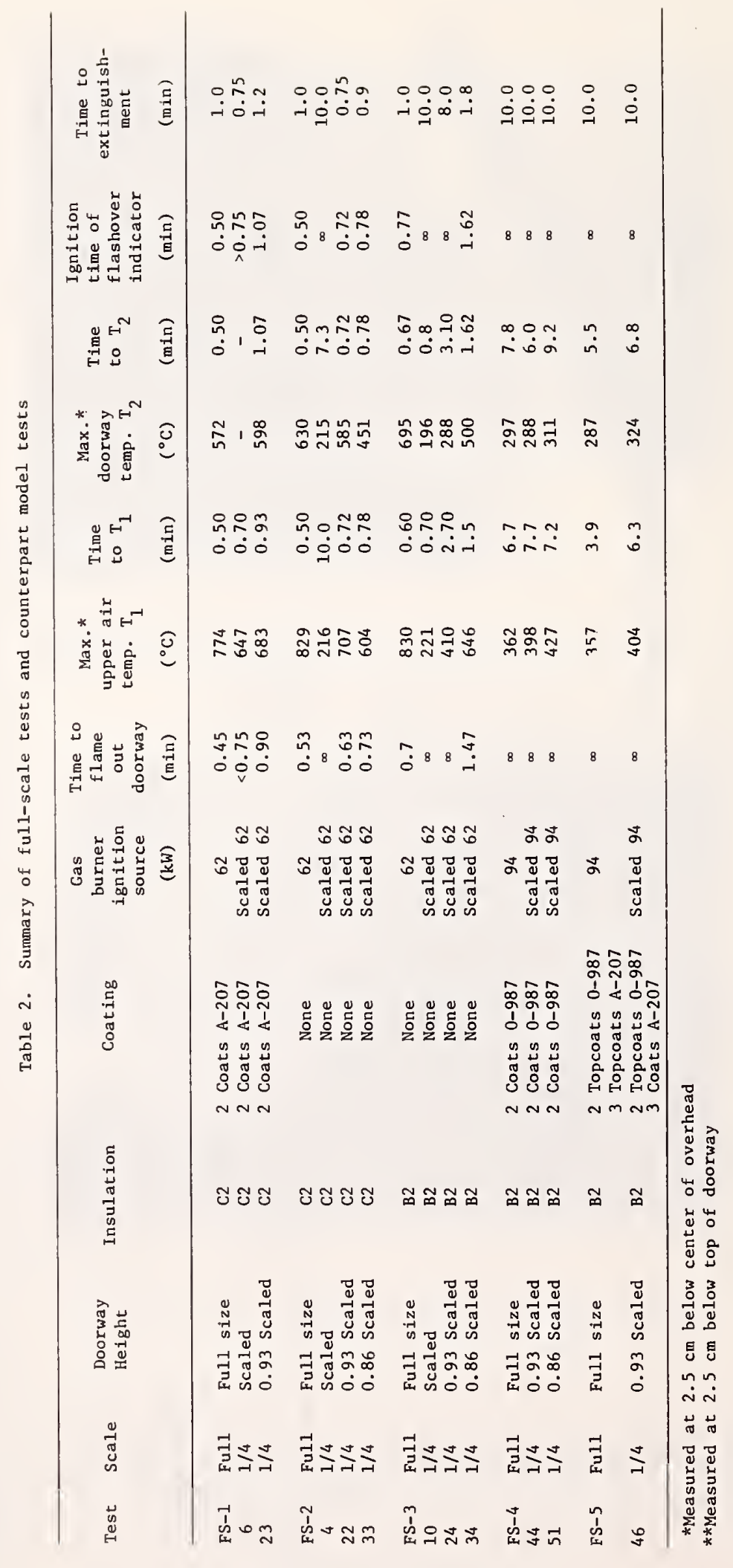




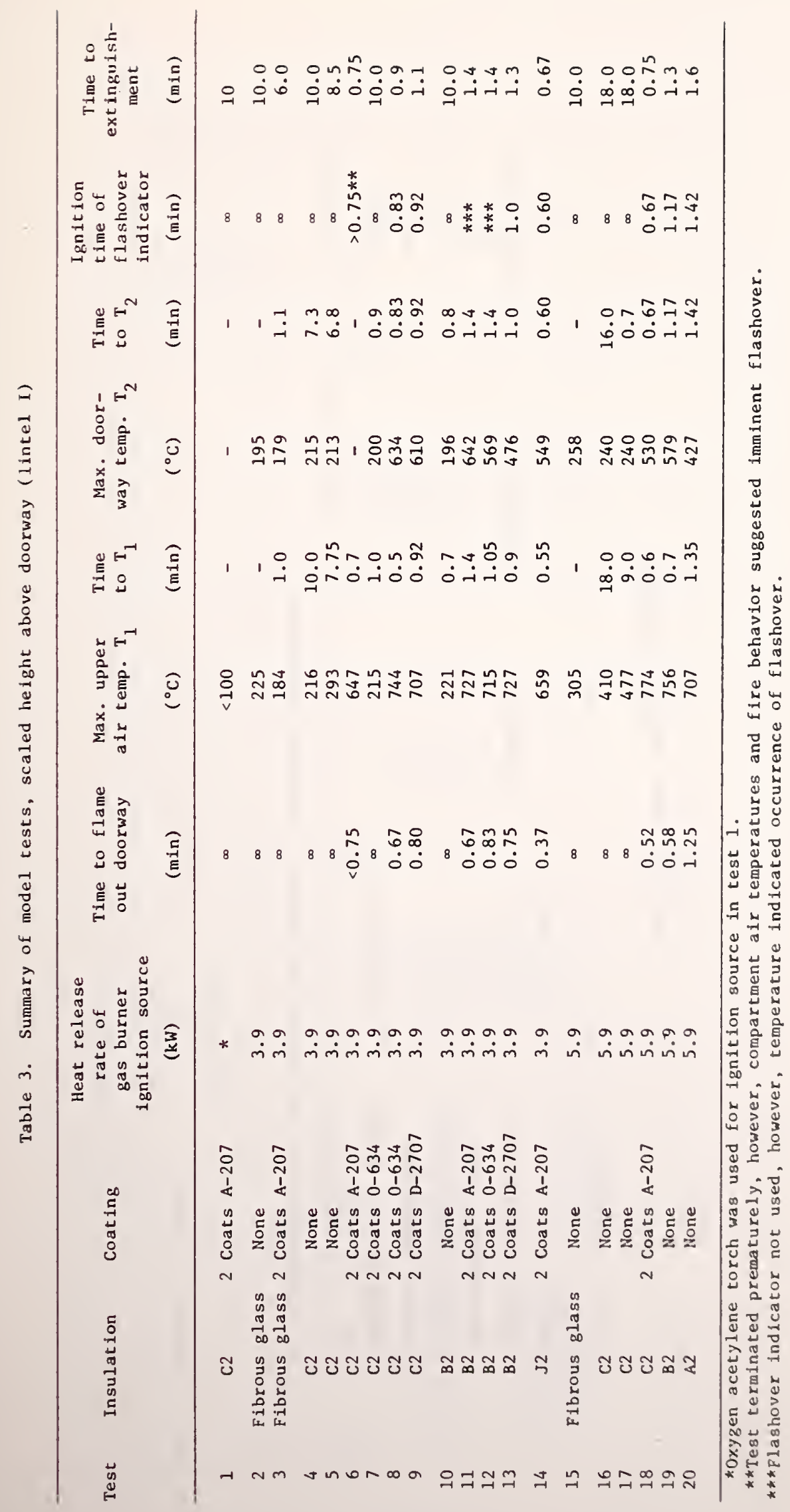




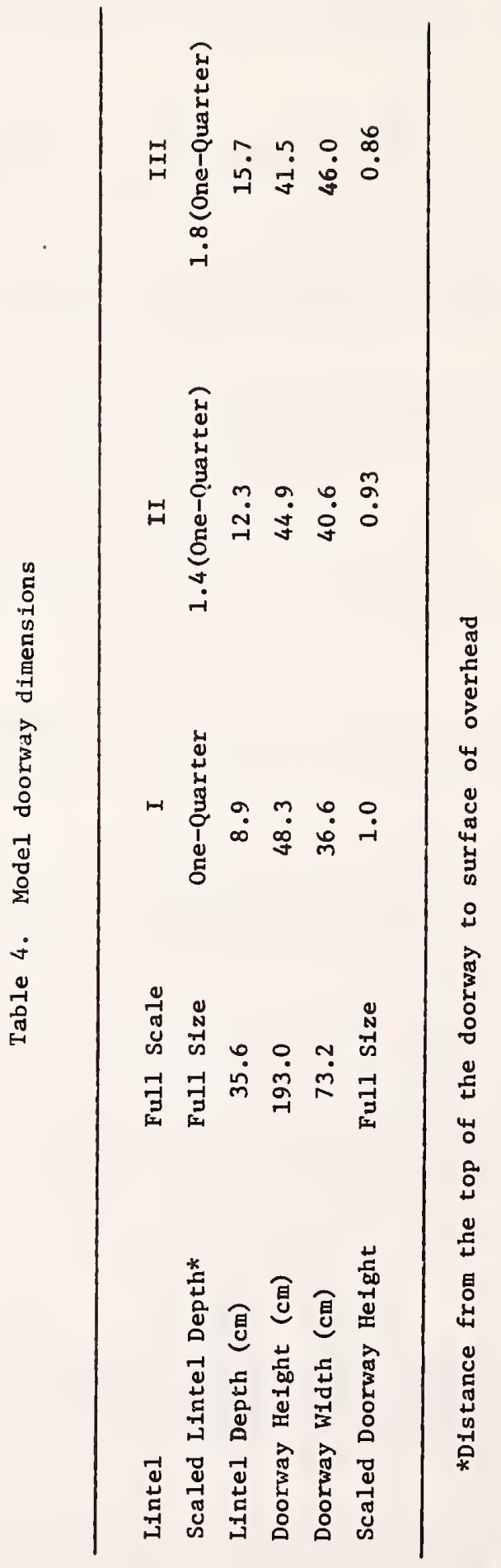




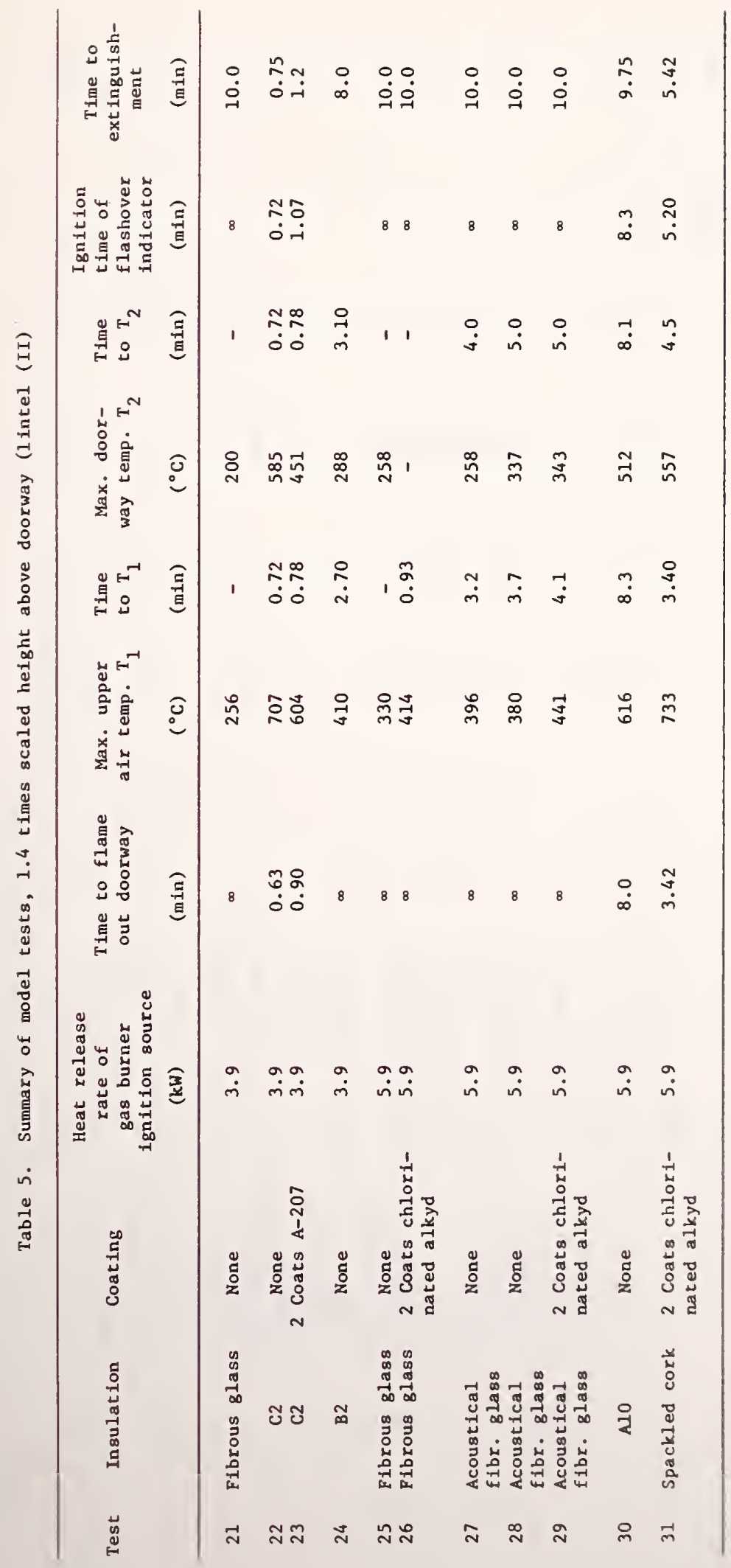




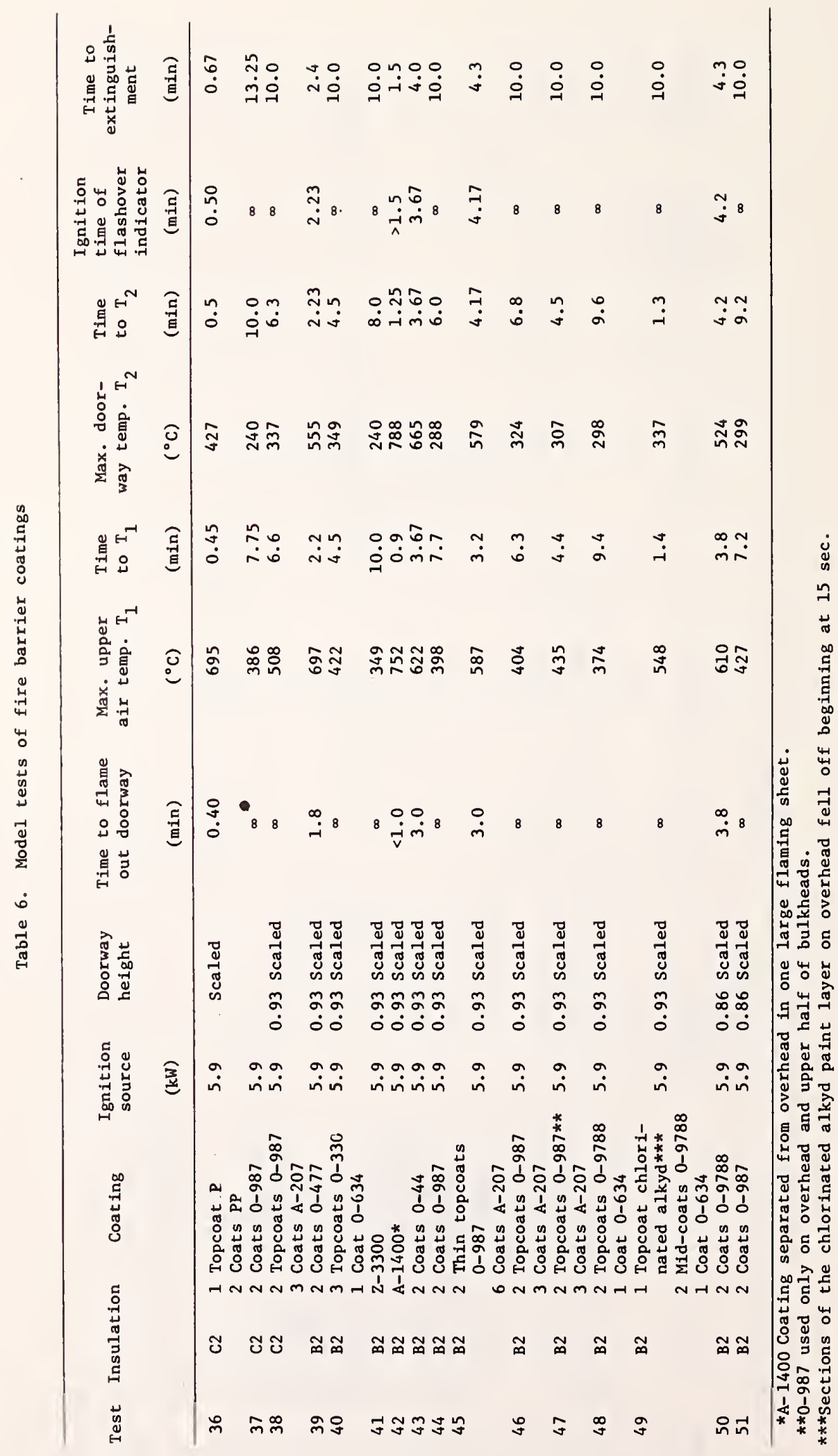




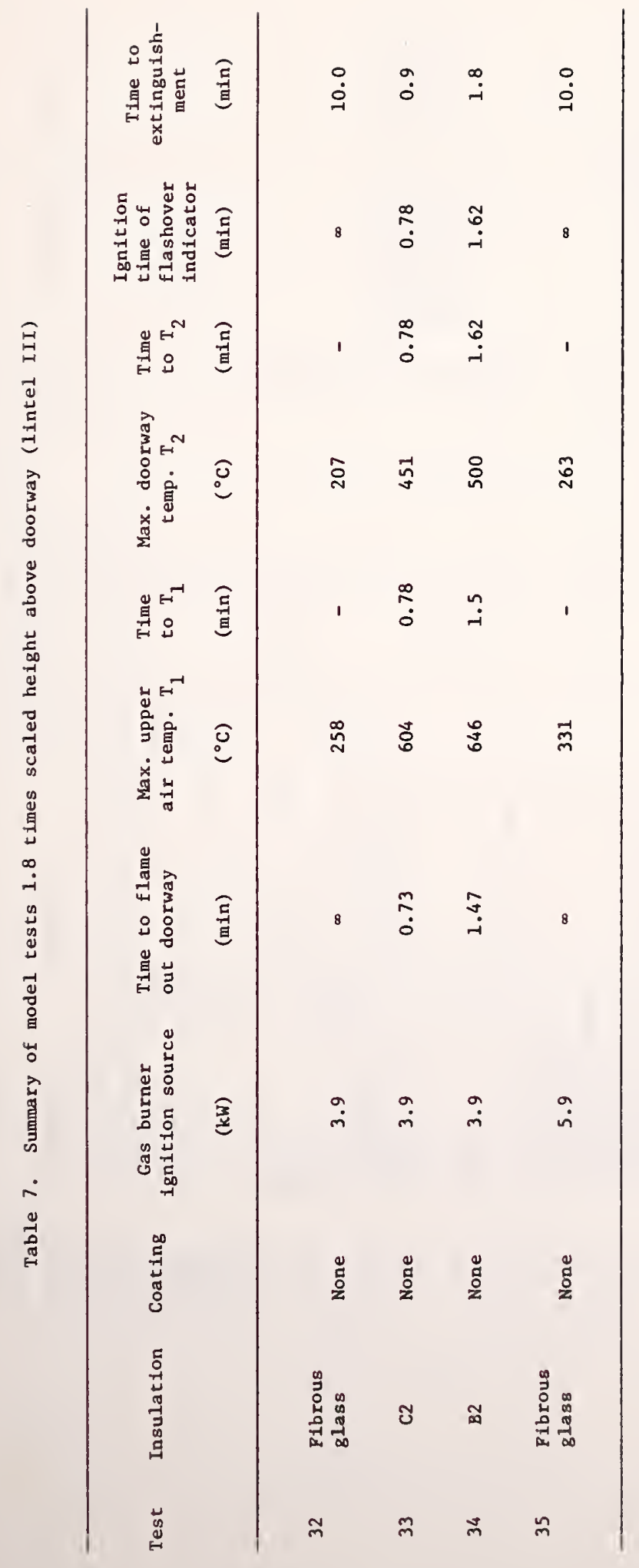




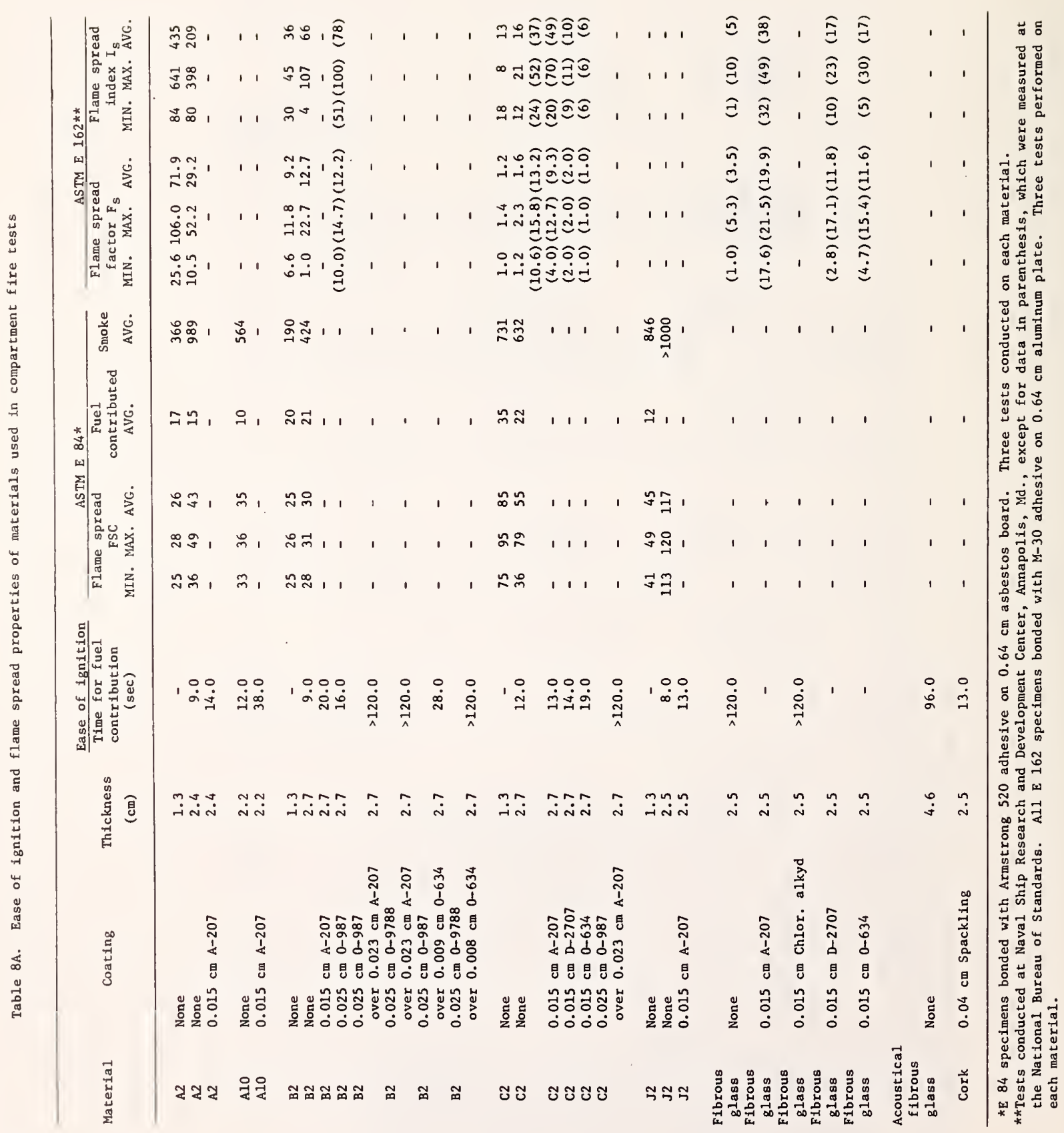




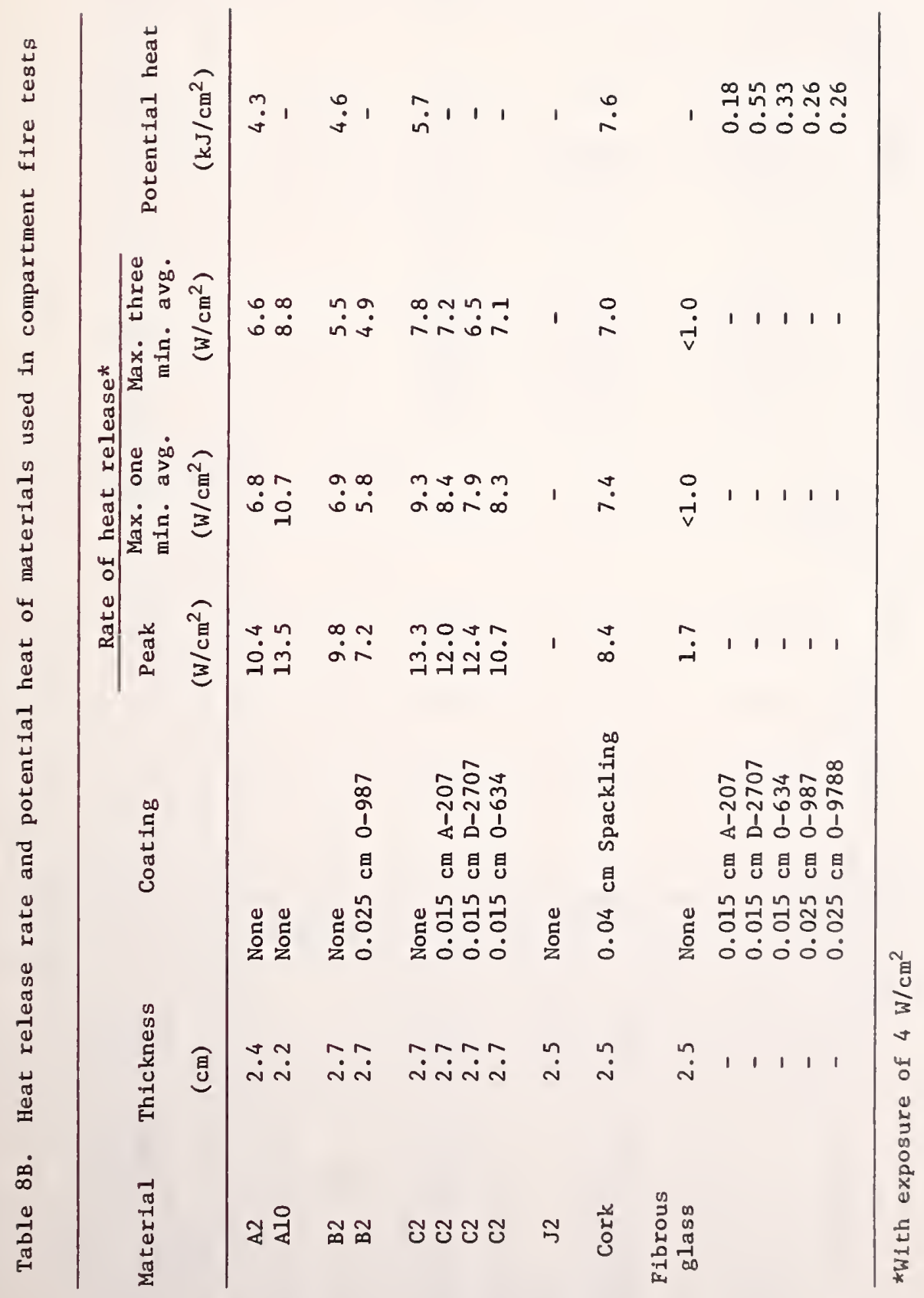




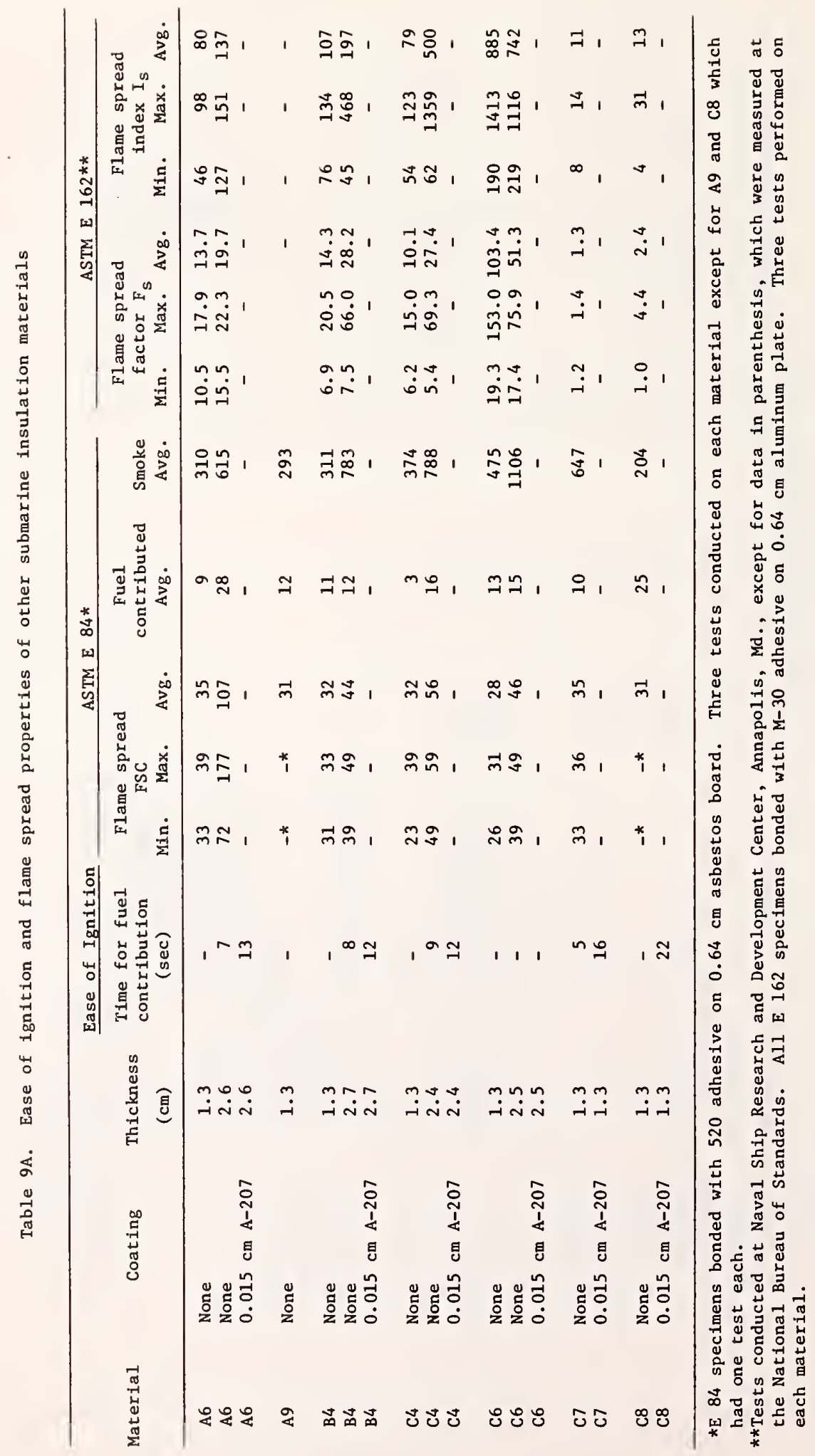


Table 9B. Heat release rate of other submarine insulation materials

\begin{tabular}{|c|c|c|c|c|c|}
\hline \multirow[b]{2}{*}{ Material } & \multirow[b]{2}{*}{$\begin{array}{c}\text { Thickness } \\
\text { (cm) }\end{array}$} & \multirow[b]{2}{*}{ Coating } & \multicolumn{3}{|c|}{ Rate of heat release* } \\
\hline & & & $\begin{array}{l}\text { Peak } \\
\left(\mathrm{W} / \mathrm{cm}^{2}\right)\end{array}$ & $\begin{array}{l}\text { Max. one } \\
\text { min. avg. } \\
\left(\mathrm{W} / \mathrm{cm}^{2}\right)\end{array}$ & $\begin{array}{c}\text { Max. three } \\
\text { min. avg. } \\
\left(W / \mathrm{cm}^{2}\right)\end{array}$ \\
\hline A6 & 2.6 & None & 11.2 & 8.9 & 8.4 \\
\hline B4 & 2.7 & None & 8.6 & 7.2 & 6.7 \\
\hline C4 & 2.4 & None & 14.5 & 12.1 & 11.1 \\
\hline C6 & 2.5 & None & 10.9 & 8.2 & 7.4 \\
\hline C7 & 1.3 & None & 12.8 & 8.4 & 6.6 \\
\hline C8 & 1.3 & None & 10.3 & 6.6 & 5.1 \\
\hline
\end{tabular}

*With exposure of $4 \mathrm{~W} / \mathrm{cm}^{2}$

Table 10. Comparison of compartment air temperatures for fire tests with three different doorway openings

\begin{tabular}{|c|c|c|c|c|c|c|}
\hline Test & $\begin{array}{c}\text { Doorway } \\
\text { height }\end{array}$ & Insulation & $\begin{array}{l}\text { Source } \\
\text { setting } \\
(\mathrm{kW})\end{array}$ & $\begin{array}{c}\text { Max. Interior } \\
\text { upper air temp. } \\
\left({ }^{\circ} \mathrm{C}\right)\end{array}$ & $\begin{array}{l}\text { Max. doorway } \\
\text { air temp. } \\
\left({ }^{\circ} \mathrm{C}\right)\end{array}$ & $\begin{array}{c}\text { Flashover } \\
\text { times } \\
(m i n)\end{array}$ \\
\hline 4 & Scaled & $\mathrm{C} 2$ & 3.9 & 216 & 215 & $\infty$ \\
\hline 5 & Scaled & $\mathrm{C} 2$ & 3.9 & 293 & 213 & $\infty$ \\
\hline 16 & Scaled & $\mathrm{C} 2$ & 5.9 & 410 & 240 & $\infty$ \\
\hline 17 & Scaled & $\mathrm{C} 2$ & $\overline{5.9}$ & 477 & 240 & $\infty$ \\
\hline 22 & 0.93 Scaled & C2 & $\overline{3.9}$ & 707 & 585 & 0.72 \\
\hline 33 & 0.86 Scaled & $\mathrm{C} 2$ & 3.9 & 604 & 451 & 0.78 \\
\hline 10 & Scaled & B2 & 3.9 & 221 & 196 & $\infty$ \\
\hline 19 & Scaled & B2 & 5.9 & 756 & 579 & 1.17 \\
\hline 24 & 0.93 Scaled & B2 & $\overline{3.9}$ & 410 & 288 & $\infty$ \\
\hline 34 & 0.86 Scaled & B2 & 3.9 & 646 & 500 & 1.62 \\
\hline
\end{tabular}




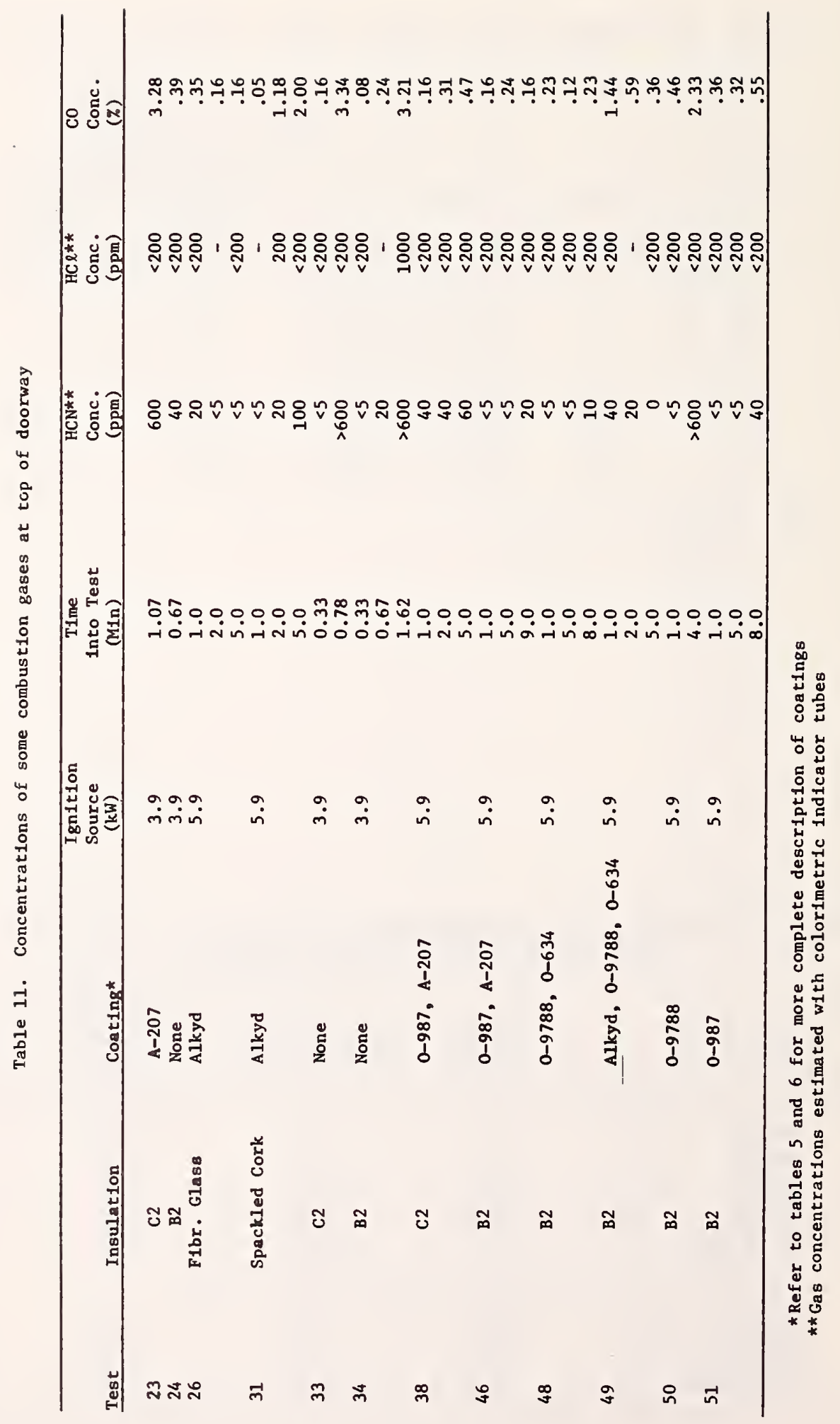


Table 12. Comparison of fire buildup in full-scale and corresponding quarter-scale compartments

\begin{tabular}{|c|c|c|c|c|c|}
\hline Test & Test & Doorway & Doorway & Ignition & Degree of \\
\hline Arrangement & No. & Lintel & Height & Setting & Fire Buildup* \\
\hline \multirow[t]{3}{*}{1.} & FS-1 & - & Full Size & Low & Flashover \\
\hline & 6 & I & Scaled & Low & Flashover \\
\hline & 23 & II & 0.93 Scaled & Low & Flashover \\
\hline \multirow[t]{4}{*}{2.} & FS-2 & - & Full Size & Low & Flashover \\
\hline & & I & Scaled & Low & $215^{\circ} \mathrm{C}$ \\
\hline & 22 & II & 0.93 Scaled & Low & Flashover \\
\hline & 33 & III & 0.86 Scaled & Low & Flashover \\
\hline \multirow{4}{*}{3.} & FS-3 & - & Full Size & Low & Flashover \\
\hline & 10 & I & Scaled & Low & $196^{\circ} \mathrm{C}$ \\
\hline & 24 & II & 0.93 Scaled & Low & $288^{\circ} \mathrm{C}$ \\
\hline & 34 & III & 0.86 Scaled & Low & Flashover \\
\hline \multirow[t]{3}{*}{4.} & FS - 4 & - & Full Size & High & $297^{\circ} \mathrm{C}$ \\
\hline & 44 & II & 0.93 Scaled & High & $288^{\circ} \mathrm{C}$ \\
\hline & 51 & III & 0.86 Scaled & High & $299^{\circ} \mathrm{C}$ \\
\hline \multirow[t]{2}{*}{5.} & FS-5 & - & Full Size & High & $287^{\circ} \mathrm{C}$ \\
\hline & 46 & II & 0.93 Scaled & High & $324^{\circ} \mathrm{C}$ \\
\hline
\end{tabular}

*Based on ignition of flashover indlcator and doorway air temperature

Table 13. Flux measurements at time of peak doorway temperature

\begin{tabular}{|c|c|c|c|c|c|}
\hline Test & $\begin{array}{l}\text { Time } \\
(\min )\end{array}$ & $\begin{array}{c}\text { Deck } \\
\left(\mathrm{W} / \mathrm{cm}^{2}\right)\end{array}$ & $\begin{array}{c}\text { Upper left bulkhead } \\
\left(\mathrm{W} / \mathrm{cm}^{2}\right)\end{array}$ & $\begin{array}{l}\text { Upper right bulkhead } \\
\qquad\left(\mathrm{W} / \mathrm{cm}^{2}\right)\end{array}$ & $\begin{array}{l}\text { Overhead } \\
\left(\mathrm{W} / \mathrm{cm}^{2}\right)\end{array}$ \\
\hline $\begin{array}{l}\text { FS-1 } \\
23\end{array}$ & $\begin{array}{l}0.50 \\
1.07\end{array}$ & $\begin{array}{l}1.73 \\
2.00\end{array}$ & $-\overline{4.9}$ & 5.5 & 5.0 \\
\hline $\begin{array}{l}\text { FS-2 } \\
33\end{array}$ & $\begin{array}{l}0.50 \\
0.78\end{array}$ & $\begin{array}{l}2.95 \\
2.53\end{array}$ & - & $\overline{7.6}$ & 5. \\
\hline $\begin{array}{l}\text { FS-3 } \\
24 \\
34\end{array}$ & $\begin{array}{l}0.67 \\
3.10 \\
1.62\end{array}$ & $\begin{array}{l}2.0 * \\
0.28 \\
2.52\end{array}$ & $\begin{array}{l}- \\
0.74 \\
5.6\end{array}$ & $\begin{array}{l}- \\
0.67 \\
6.7\end{array}$ & $\begin{array}{l}- \\
0.66 \\
5.2\end{array}$ \\
\hline $\begin{array}{l}\text { FS-4 } \\
44 \\
51\end{array}$ & $\begin{array}{l}7.8 \\
6.0 \\
9.2\end{array}$ & $\begin{array}{l}0.19 \\
0.46 \\
0.56\end{array}$ & $\begin{array}{l}- \\
0.75 \\
1.5\end{array}$ & $\begin{array}{c}- \\
- \\
1.3\end{array}$ & $\begin{array}{l}- \\
- \\
1.4\end{array}$ \\
\hline $\begin{array}{l}\text { FS-5 } \\
46\end{array}$ & $\begin{array}{l}5.5 \\
6.8\end{array}$ & $\begin{array}{l}0.17 \\
0.36\end{array}$ & $\begin{array}{c}0.59 \\
-\end{array}$ & $\begin{array}{c}0.58 \\
-\end{array}$ & $\begin{array}{l}0.63 \\
0.62\end{array}$ \\
\hline
\end{tabular}

*Also the value at $0.77 \mathrm{~min}$ when flashover occurred. 
Table 14. Calculated mass balance across doorway for three compartment fires

\begin{tabular}{lccc}
\hline Test & $\begin{array}{c}\text { Time } \\
(\mathrm{min})\end{array}$ & $\begin{array}{c}\text { Mass flow in } \\
(\mathrm{kg} / \mathrm{min})\end{array}$ & $\begin{array}{c}\text { Mass flow out } \\
(\mathrm{kg} / \mathrm{min})\end{array}$ \\
\hline \multirow{3}{*}{ FS-1 } & 0.25 & 3 & 46 \\
& 0.50 & 30 & 79 \\
FS-2 & 0.25 & 2 & 39 \\
& 0.50 & 18 & 61 \\
FS-4 & 0.25 & 3 & 15 \\
& 0.50 & 28 & 31 \\
& 1.0 & 31 & 25 \\
& 5.0 & 43 & 47 \\
& 8.0 & 39 & 52 \\
\hline
\end{tabular}

Table 15. Comparison of measured model and prototype inflow air velocities near bottom of doorway

\begin{tabular}{lccc}
\hline $\begin{array}{c}\text { Time } \\
\text { (min) }\end{array}$ & $\begin{array}{c}\text { Model* } \\
\text { (m/min) }\end{array}$ & $\begin{array}{c}\text { Prototype FS-4 } \\
\text { Velocity } \\
\text { (m/min) }\end{array}$ & $\begin{array}{r}\text { Velocity Ratio } \\
\text { Prototype/Model }\end{array}$ \\
\hline 0.25 & 14 & 6 & 0.4 \\
0.50 & 16 & 34 & 2.1 \\
5.0 & 20 & 49 & 2.5 \\
6.0 & 23 & 55 & 2.4
\end{tabular}

* Averaged values from tests 44 and 51. 


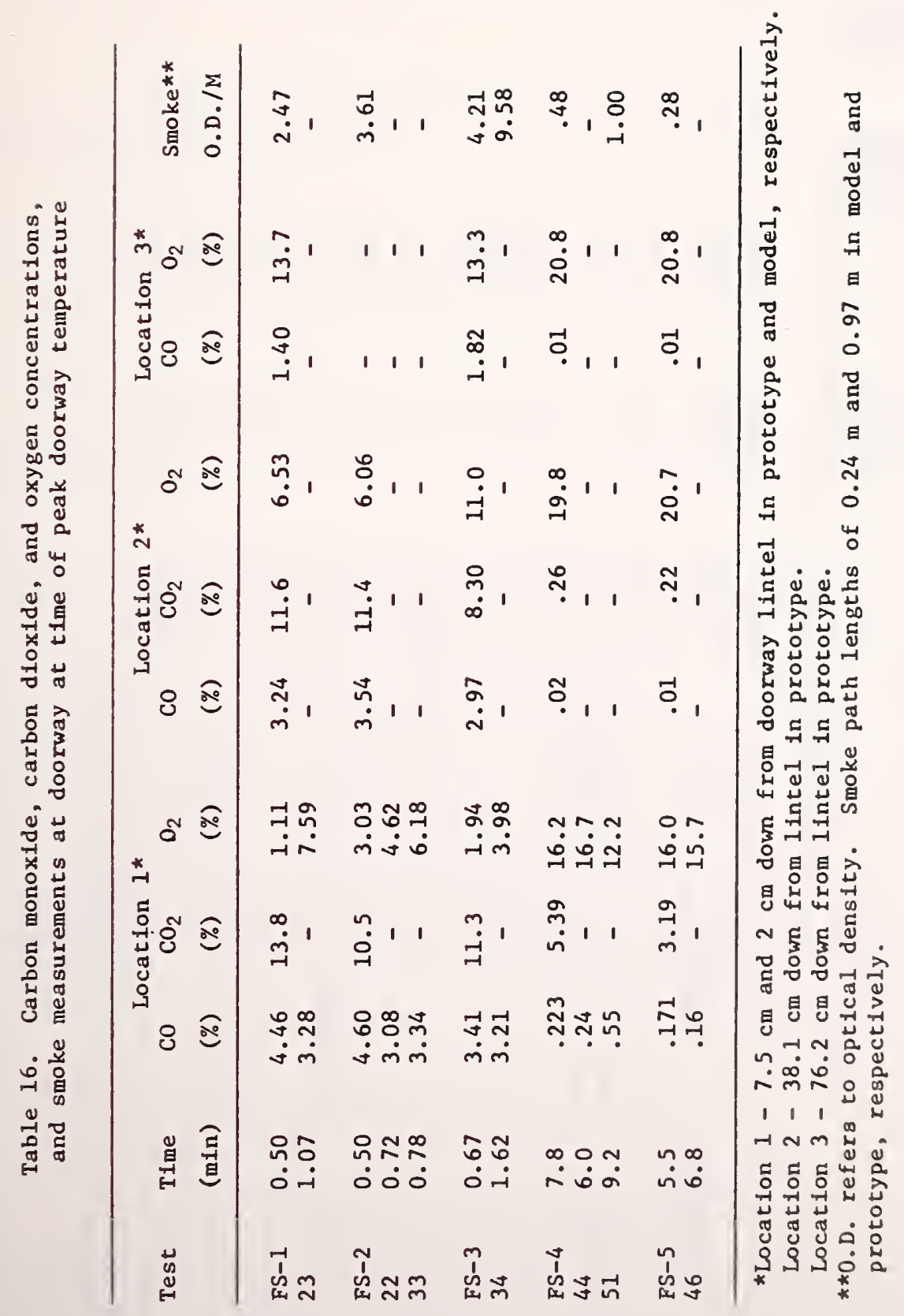




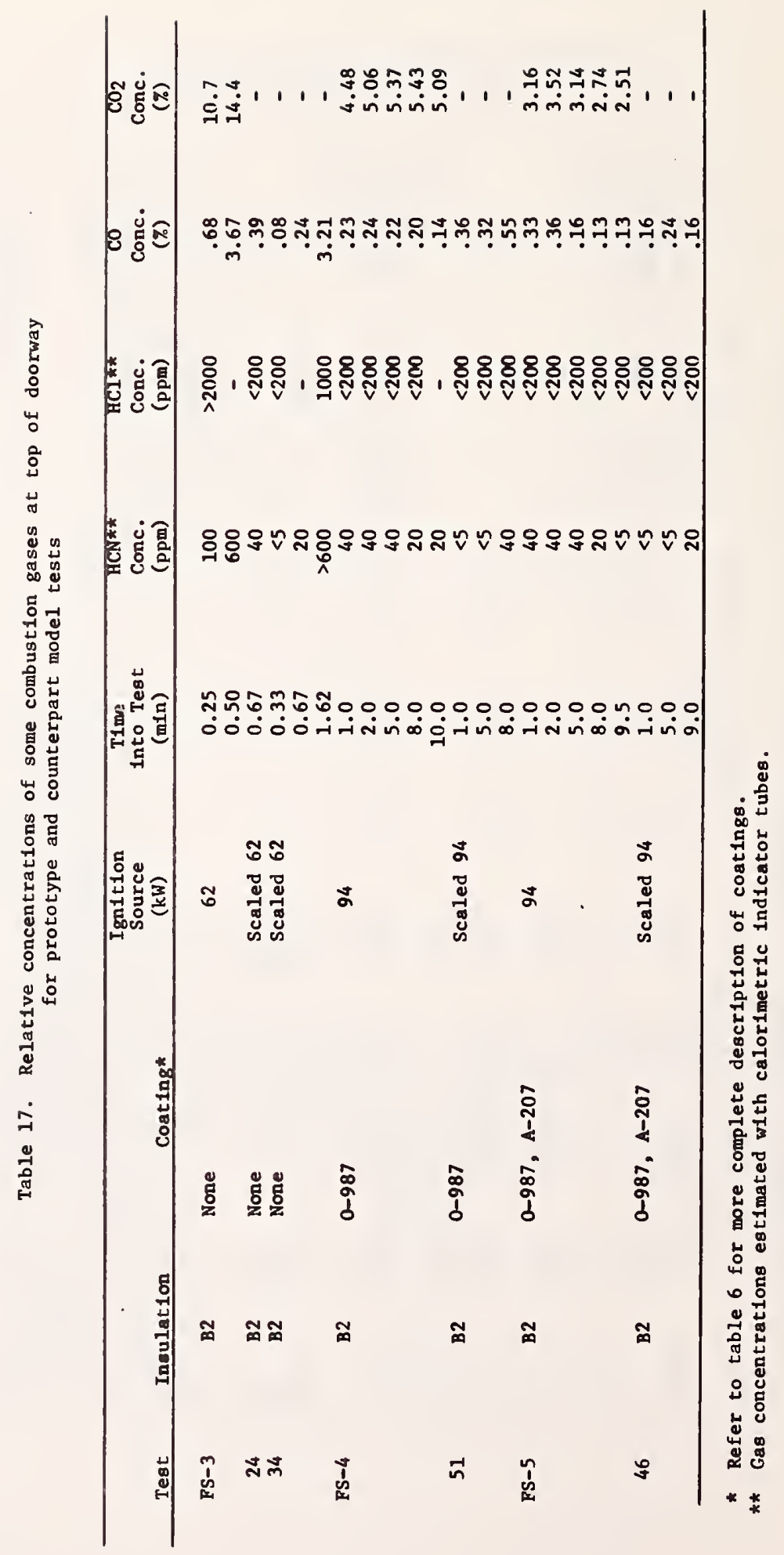


U.S. DEPT. OF COMM.

BIBLIOGRAPHIC DATA SHEET
1. PUBLICATION OR REPORT NO.

NBSIR $78-1584$

4. TITLE AND SUBTITLE

5. Publication Date

May 1979

SUBMARINS COMPARTMENT FIRE STUDY-FIRE PERFORMANCE EVALUATION OF HULL INSULATION

4. Perionalas Pranization cote

8. Performing Organ. Report No.

7. AUTHOR(S)

B. T. Lee and J. N. Breese

9. PERFORMING ORGANIZATION NAME AND ADDRESS

1. Propect Task/Fork thit No.

NATIONAL BUREAU OF STANDARDS

DEPARTMENT OF COMMERCE

11. Contract/Grant No.

WASHINGTON, DC 20234

12. SPONSORING ORGANIZATION NAME AND COMPLETE ADDRESS (Streot, City, State, $z I P$ )

Ship Damage Prevention and Control

Naval Sea Systems Command

Department of the Navy

Washington D.C. 20362

15. SUPPLEMENTARY NOTES

Document describes a computer program; SF-185, FIPS' Software Summary, is attached.

16. ABSTRACT (A 200-word or loos factual aummary of most olgrificant information. If document inciudes a significant bibliography of literature survey, mention it here.)

Certain foam rubber materials which are currently used to insulate the interior of submarines are shown to possess a serious fire risk potential. Flame spread tests often do not adequately reflect the fire hazard potential of these materials. It is shown that compartment fire testing is the only satisfactory method of evaluating these kinds of materials at the present time.

Fire barrier coatings for protecting these hull insulations are also investigated. Two candidate coatings are found to prevent full fire involvement of an insulated compartment following a moderately large flame exposure and at the same time meet the Navy's elasticity requirement for submarine application. The study includes comparisons of model and prototype compartment fire behavior and demonstrates the practicality of using quarter-scale fire tests for screening compartment finish materials.

17. KEY WORDS (oix to twelve ontrioo; alphabetical order; capitallze only the firet letter of the flrot key word unlese a proper name: aparated by omicolona) heat release; interior finish; laboratory fire tests; material 1 gnitability; submarine compartment.
18. AVAILABILITY
X. Unlimited

For Official Distribution. Do flot Release to NTIS

Order From Sup. of Doc., U.S. Government Printing Office, Washington, DC 20402, SD Stock No. SNO03-003-

X Order From National Technical Information Service (NTIS), Springfield, VA, 22161

\begin{tabular}{|l|c|}
\hline $\begin{array}{l}\text { 19. SECURITY CLASS } \\
\text { (THIS REPORT) } \\
\text { UNCLASSIFIED }\end{array}$ & $\begin{array}{c}\text { 21. NO. OF } \\
\text { PRINTED PAGES } \\
40\end{array}$ \\
\hline $\begin{array}{l}\text { 20. SECURITY CLASS } \\
\text { (THIS PAGE) } \\
\text { UNCLASSIFIED }\end{array}$ & 22 . PrICe \\
\end{tabular}



